\title{
Parasite histones mediate leak and coagulopathy in cerebral malaria
}

Christopher A Moxon ${ }^{1,2 *^{+}}$, Yasir Alhamdi ${ }^{1+}$, Janet Storm ${ }^{3}$, Julien MH Toh ${ }^{4}$, Joo Yeon $\mathrm{Ko}^{5}$, George Murphy ${ }^{6}$, Terrie E Taylor ${ }^{7,8}$, Karl B Seyde ${ }^{5,6}$, Sam Kampondeni ${ }^{9}$, Michael Potchen ${ }^{10}$, James S. O'Donnell ${ }^{11}$, Niamh O'Regan $^{11}$, Guozheng Wang ${ }^{1}$, Guillermo García-Cardeña ${ }^{12}$, Malcolm Molyneux ${ }^{3,13}$, Alister Craig $^{3}$, Simon T Abrams ${ }^{1 \ddagger}$, Cheng-Hock Toh ${ }^{1 \ddagger}$

\section{Affiliations:}

${ }^{1}$ Institute of Infection and Global Health, University of Liverpool, UK

${ }^{2}$ Wellcome Centre for Integrative Parasitology, Institute of Infection, Immunity and Inflammation, College of Medical Veterinary \& Life Sciences, University of Glasgow, UK ${ }^{3}$ Liverpool School of Tropical Medicine, Liverpool, UK

${ }^{4}$ University of Sheffield Medical School, UK

${ }^{5}$ Department of Dermatology, Hanyang University Hospital and Hanyang University College of Medicine, Seoul, South Korea

${ }^{6}$ Program in Dermatopathology, Department of Pathology, Brigham and Women's Hospital, Harvard Medical School, Boston, MA, USA

${ }^{7}$ College of Osteopathic Medicine, Michigan State University, East Lansing, USA

${ }^{8}$ Blantyre Malaria Project, University of Malawi College of Medicine, Blantyre, Malawi

${ }^{9}$ University of Malawi College of Medicine, Blantyre, Malawi

${ }^{10}$ Univeristy of Rochester, Department of Radiology, Rochester, NY, USA

${ }^{11}$ Irish Centre for Vascular Biology, Royal College of Surgeons in Ireland, Dublin, Ireland.

${ }^{12}$ Center for Excellence in Vascular Biology, Department of Pathology, Brigham and

Women's Hospital and Harvard Medical School, Boston, MA, USA

${ }^{13}$ Malawi-Liverpool-Wellcome Clinical Research Programme, University of Malawi College of Medicine, Blantyre, Malawi

*To whom correspondence should be addressed: christopher.moxon@glasgow.ac.uk ${ }^{\dagger}$ These authors contributed equally to this work, ${ }^{\ddagger}$ These authors contributed equally to this work

Short Title: Histones in cerebral malaria

Keywords: Malaria, Severe, Cerebral, Endothelium, coagulation, brain, swelling, blood brain barrier, histones 
43 Abstract: Coagulopathy and leak, specific to the brain vasculature, are central pathogenetic 44 components of cerebral malaria (CM). It is unclear how the parasite, Plasmodium falciparum, 45 triggers these processes. Extracellular histones, released from damaged host cells, bind to cell 46 membranes, causing coagulation activation, platelet aggregation and vascular leak in diverse 47 critical illnesses. In CM patients, serum histones correlate with fibrin formation, 48 thrombocytopenia, and endothelial activation; predicting brain swelling on MRI and fatal 49 outcome. Post-mortem, histones bind to the luminal vascular surface, co-localizing with $P$. 50 falciparum-infected erythrocytes (IE), and with thrombosis and leak. Purified $P$. 51 falciparum histones or serum from patients with CM cause toxicity and barrier disruption in cultured human brain endothelial cells, reversed by anti-histone antibodies and nonanticoagulant heparin. These data implicate parasite histones as a key trigger of fatal brain swelling in CM. Neutralizing histones with agents such as non-anticoagulant heparin warrant exploration to prevent brain swelling and improve outcome.

56

57

58

59

60

61

62

63

64

65

66

67

68

69

70 


\section{Introduction}

Cerebral malaria (CM) is a severe complication of Plasmodium falciparum infection. Despite effective antimalarial drugs, $10-20 \%$ of children developing CM die (1), contributing to 400,000 malarial deaths per year, mostly in children in sub-Saharan Africa (2). Recent MRI studies implicate blood brain barrier (BBB) breakdown and brain swelling in the causal pathway to death $(3,4)$. Death typically occurs in the first 24 hours after admission (5), with children who do not reach critical levels of brain swelling frequently recovering rapidly. BBB stabilization, through targeting causal pathways to vascular leak in the brain, could halt this brain swelling and reduce mortality.

A defining feature of $\mathrm{CM}$ is cytoadherence of $P$. falciparum infected erythrocytes (IE) to endothelial cells (EC) and sequestration in the microvasculature (1). In vivo retinal imaging (6, $7)$, post-mortem histology $(8,9)$ and in vitro data $(10)$ demonstrate spatial-temporal links between sequestration and microvascular leak and thrombosis, and coagulopathy predicts fatal outcome in $\mathrm{CM}(11,12)$. Post-mortem studies in African children demonstrate sequestration in multiple organs, whereas leak and coagulopathy are most prominent in the brain $(9,13,14)$; implying that sequestration provides a parasite stimulus for vascular leak and coagulopathy and that the response to this stimulus is different in the brain $(8,15)$. The nature of this parasite stimulus remains unclear.

Extracellular histones, released by damaged or immune activated host cells have emerged as critical EC damage mediators in diverse severe illnesses including sepsis (16), inflammatory conditions (17) and trauma (18). Hallmark features of histone toxicity are thrombocytopenia (19) and microvascular thrombosis and leak $(16,18)$. In patients with sepsis or trauma, histone levels correlate with clinical severity scores (20), thrombocytopenia (19), coagulation activation $(18,20,21)$ and predict outcome $(22)$. In animal models of sepsis or trauma, the release of extracellular histones are causal in these processes and in fatal outcome, which are prevented by anti-histone antibodies $(18,20,23)$, heparins, including non-anticoagulant heparins (24) (which neutralize histones) and by activated protein C (aPC, which degrades histones) (16). In mice, infusion of exogenous histones of $>30 \mathrm{mg} / \mathrm{kg}$ are toxic and of $>60 \mathrm{mg} / \mathrm{kg}$ are fatal; histologically histones are observed to bind to the endothelium, associated with microvascular coagulopathy and vascular leak (22). In vitro, histone binding to the EC membrane causes toxicity and barrier disruption $(22,23)$. The cationic domain of histones also induces Weibel Palade body exocytosis, endothelial activation and thrombocytopenia through platelet aggregation on von Willebrand Factor strings (25). Histones further induce a procoagulant phenotype through upregulation of endothelial tissue factor (26). By an unknown mechanism, histones decrease cell surface thrombomodulin in vitro (27), and induce thrombomodulin shedding in vivo (18). induced by histones in other conditions $(16,22)$ and those at sites of sequestration in $\mathrm{CM}$, in 
particular the brain $(8,9,14)$, we hypothesized that histones might be an important causal factor in CM pathogenesis. P. falciparum, as mammalian cells, contains histones (H2A, H2A.Z, $\mathrm{H} 2 \mathrm{~B}, \mathrm{H} 3, \mathrm{H} 4$ ), packaged in nucleosomes with DNA. Following sequestration, intraerythrocytic merozoites multiply 16-24 times to form a schizont, increasing nuclear material, including histones, by an order of magnitude. Schizonts rupture releasing their contents, extruding $P$. falciparum histones in vitro into culture medium (28). Similar to mammalian histones, on cultured ECs, purified plasmodial histones cause inflammatory pathway activation, toxicity and barrier disruption (28). Therefore, histones may link sequestration and vascular pathology in $\mathrm{CM}$; sequestration bringing histone-packed schizonts in contact with the endothelial surface, concentrating exposure to extruded histones many fold. The brain might be particularly vulnerable to this mechanism. Firstly, there are high levels of sequestration in the brain in CM $(14,29,30)$. Secondly the brain may have reduced capacity to breakdown histones: the human brain has reduced innate capacity to produce activated protein $\mathrm{C}$ (aPC) (31), owing to low constitutive thrombomodulin and endothelial protein $C$ receptor (EPCR) expression $(32,33)$, the receptors involved in aPC production. Moreover, parasite variants associated with the development of CM utilize EPCR as a binding receptor (34, 35), interfering with its function and the production of $\operatorname{aPC}(35,36)$. Thus histones released by IE would be predicted to concentrate and be particularly toxic in the brain.

Supporting that $P$. falciparum histones may be released in patients with malaria, nucleosomes have been detected in the plasma of South-East Asian adults with malaria, which were higher in severe cases (28). However the association between nucleosomes (which have minimal toxicity (21)) and free histones is variable and it was not identified whether these nucleosomes were of host or parasite origin, or whether they were active. Thus, it remains uncertain whether significant levels of parasite histones are produced in vivo in patients with malaria and there are no data assessing the association between histones and clinical or laboratory indicators of severity or coagulation and leak, nor data to assess whether plasmodial histones bind in the vasculature at sites of sequestration.

Here we address these gaps. Using detailed laboratory, clinical and MRI imaging data we link histone levels in the blood to fibrin formation, endothelial activation and thrombocytopenia and to brain swelling and fatal outcome. Through post-mortem brain tissue samples from CM cases we show marked correlation between sequestration and the deposition of histones on the endothelial surface, and co-localisation with thrombosis and leak in the brain vasculature. We then demonstrate a causal role of $P$. falciparum histones in these processes through ex vivo experiments.

\section{Methods}

\section{Patients and blood samples}

Children aged 6 months - 16 years were recruited at Queen Elizabeth Central Hospital, Blantyre Malawi between January 2010 and August 2011. Inclusion criteria are described 
previously (8). Children who met WHO criteria for CM underwent funduscopic examination by an ophthalmologist: characteristic retinal changes indicate sequestration of IE in the brain(37) and distinguish retinopathy-positive CM with stringently defined CM (CM-pos) from cases with retinopathy negative CM (CM-neg), who are more likely to have an alternative diagnosis (1), to which malaria makes a variable contribution (38) and thus may have a different coma aetiology. Uncomplicated malaria and mild aparasitemic febrile illness cases were children with acute febrile illness without signs of organ compromise recruited from the hospital Accident and Emergency department (Emergency Room). Healthy controls were children attending elective surgery. Venous blood was collected at enrolment into plain or sodium citrate tubes and serum and plasma prepared as previously described (39), stored at $-80^{\circ} \mathrm{C}$ until assays were performed. Circulating histone levels were quantified by a custom immunoblot assay (18-20) and Osteoprotegrin, Fibrin monomers, F1+2 fragment by ELISA as described previously $(8,11,40)$.

There were no prior data on histone levels in $\mathrm{CM}$ on which to base a power calculation. The number of samples to be analysed was determined a priori, at the time of study design, based on the availability of samples and deemed to be appropriate based on comparison of histones levels in other conditions. All samples were processed and analysed together.

\section{$M R I$ scans and scoring of brain swelling}

MRI images were acquired using a 0.35-Tessla Signa Ovation Excite MRI scanner (General Electric). Images were scored independently by two radiologists who were blinded to patient disease group and outcome. A score from $1-8$ was assigned to each scan, based on cerebral hemisphere swelling, using pre-specified criteria - described previously (3). We divided patients into 4 groups on the basis of this 8-point score: Score 1-3, No brain swelling; 4-5, mild brain swelling; 6 , moderate brain swelling and 7-8, severe brain swelling. A number of children did not have MRI scans. When this was because they recovered from coma within 12 hours we deemed it likely that they did not have significant brain swelling and included them in category 1 . Other MRI scans were not performed for several reasons (e.g. patient clinical unstable, equipment issues), we could not reasonably assign a category, and missing data were handled by listwise deletion.

\section{Isolation and purification of $P$. falciparum histones}

ITG mature IE were lysed with saponin and $P$. falciparum histones $(\mathrm{H} 2 \mathrm{~A}, \mathrm{H} 2 \mathrm{~B}, \mathrm{H} 3, \mathrm{H} 4)$ purified using a Kit (Active Motif). Protein concentrations were determined by Biorad Protein Assay, using bovine serum albumin and purified calf histones (Roche) standards and purity examined by SDS-PAGE and Coomassie staining (>95\% pure; Fig. S3)

\section{Mass spectrometry sample preparation}

Purified P. falciparum and human histones (New England Biolabs) $(6 \mu \mathrm{g})$, normal serum, histone spiked serum and CM patient serum were separated by $15 \%$ SDS-PAGE and stained 
with Coomassie brilliant blue. The excised gel slices $(<35 \mathrm{kDa})$ from SDS-PAGE, were cut into $1 \mathrm{~mm}^{3}$ plugs, transferred to a microtube and fully de-stained using $25 \mathrm{mM}$ Ambic alternately with Ambic/MeCN (2:1). Cysteine reduction was performed by adding $100 \mu \mathrm{L}$ DTT solution $(1.5 \mathrm{mg} / \mathrm{mL})$ and incubated at $60^{\circ} \mathrm{C}$ for $60 \mathrm{~min}$. Samples were centrifuged and the supernatant was discarded. Alkylation was performed by the addition of $100 \mu \mathrm{L}$ iodoacetamide $(10 \mathrm{mg} / \mathrm{mL})$ for $45 \mathrm{~min}$ (protected from light). Samples were centrifuged and the supernatant discarded. Gel plugs were then washed with Ambic $(25 \mathrm{mM})$ for $15 \mathrm{~min}$ at $37^{\circ} \mathrm{C}$. To fully dehydrate the gel plugs, samples were washed with MeCN. In-gel digestion was performed by adding $100 \mu \mathrm{L}$ of trypsin (12.5ng/ $\mu \mathrm{L}$ in $25 \mathrm{mM}$ Ambic) to each sample with overnight incubation at $37^{\circ} \mathrm{C}$, and reactions terminated by the addition of $10 \mu \mathrm{L}$ formic acid ( $1 \%$ final concentration). The solutions surrounding the gel plugs (containing the tryptic peptides) were retained for analysis. To extract additional peptides from the gel plugs, a further incubation with a solution containing water:MeCN:FA (50:49:1) and then MeCN:FA (80:19:1) was performed. Finally, solutions were pooled and dried to a $10 \mu \mathrm{L}$ solution.

\section{Liquid Chromatography-mass spectrometry analysis}

Analysis was performed using an Ultimate 3000 RSLC ${ }^{\text {TM }}$ nano system (Thermo Scientific, Hemel Hempstead), coupled to a QExactive- $\mathrm{Hf}^{\mathrm{TM}}$ mass spectrometer (Thermo Scientific). Samples were loaded onto a trapping column (Thermo Scientific, PepMap100, C18, $300 \mu \mathrm{m} \mathrm{X}$ $5 \mathrm{~mm}$ ), using partial loop injection, for seven minutes at a flow rate of $9 \mu \mathrm{L} / \mathrm{min}$ with $0.1 \%$ (v/v) FA. Samples were then resolved on the analytical column (Easy-Spray C18 $75 \mu \mathrm{m} \times 500$ $\mathrm{mm} 2 \mu \mathrm{m}$ column) using a gradient of $97 \%$ A $(0.1 \%$ formic acid) $3 \%$ B (99.9\% ACN $0.1 \%$ formic acid) to $60 \%$ A $40 \%$ B over $15 \mathrm{~min}$ at a flow rate of $300 \mathrm{~nL} \mathrm{~min}-1$. The data-dependent program used for data acquisition consisted of a 70,000 resolution full-scan MS scan (AGC set to $1 \mathrm{x}$ $10^{6}$ ions, with a maximum fill time of $20 \mathrm{~ms}$ ) the 10 most abundant peaks were selected for MS/MS using a 35,000 resolution scan (AGC set to $1 \times 10^{5}$ ions with a maximum fill time of $100 \mathrm{~ms}$ ) with an ion-selection window of $3 \mathrm{~m} / \mathrm{z}$ and a normalized collision energy of 28 . To avoid repeated selection of peptides for MS/MS the program used a 15 second dynamic exclusion window. Sequence alignment was performed in PEAKs software (v8.5) against both P. falciparum and Homo sapiens databases. Once species-specific peptides were identified they were further verified using Skyline analysis software for quantification (comparisons between the specific amino acid sequences of $P$. falciparum and Homo sapiens histone proteins illustrated in Fig S4).

245 Brain tissue samples of parietal cortex were collected at autopsy from Malawian children dying with encephalopathic illness and were formalin fixed and paraffin embedded as described previously (9). Based on clinical information and autopsy findings the cause of death was determined for each case by a clinical pathologist. We used samples classified into 
of IE in cerebral vessels and in whom no alternative cause of death was identified at autopsy; 2) 'Faux $\mathrm{CM}^{\prime}$ ' (CM3) - met the case definition for $\mathrm{CM}$ during life but who had no visible sequestration of IE in cerebral vessels and in whom at autopsy another cause of coma and death was identified in all cases; 3) Aparasitemic non-malarial coma comatose patients who had no detectible malaria parasites in blood or tissue.

Cortical sections ( $4 \mu \mathrm{m}$ in thickness) were stained for histones and fibrinogen. Heat-induced antigen retrieval in citrate buffer $(\mathrm{pH} 6.0)$ was performed prior to incubation with primary antibodies: anti-histone H3 (Abcam); anti-Fibrinogen (Thermofisher)). Bound primary antibody was detected with an immunoperoxidase kit (EnVision Plus; Dako). Negative controls without primary antibody were used for all samples to confirm specificity. Immunohistochemistry was performed on all cases by a single investigator blinded to histologic diagnosis. Slides were scored by 3 investigators blinded to histological classification. 70 random vessels were scored from each slide. IE sequestration for each vessel was scored as: negative (0); positive but $<50 \%$ of the vessel lumen $(+)$ or $>50 \%$ of the vessel lumen $(++)$. Histone membrane staining for each vessel was scored as absent (0); weak (+) or strong (++). Fibrinogen extravasation as a marker of leak was scored for each vessel as absent or present.

There were no prior data on histone staining in post-mortem samples in $\mathrm{CM}$ or in other conditions. The numbers of samples to be stained and the numbers of vessels to be scored were based on numbers from previous studies comparing factors in CM. Numbers for staining and analysis were determined $a$ priori and were not altered. Samples were stained together to avoid batch effects.

\section{Endothelial cell culture, endothelial cell damage assays and barrier function assays}

Primary HBMEC (Cell Systems, US) were cultured in $1 \%$ gelatin-coated flasks, in Complete Medium containing 10\% FBS (Cell Systems, US) as per manufacturer's instructions.

For toxicity assays, HBMEC were treated with either purified histones in Cell Systems media with $2 \%$ serum or serum from healthy controls or patients (diluted 1:1 with PBS) for 1 hour at $37^{\circ} \mathrm{C}$, under $5 \% \mathrm{CO}_{2}$. Cell viability was determined by propidium iodide (PI) staining and quantified using flow cytometry. Cell toxicity in patient samples was calculated as the percentage of cells that were $\mathrm{PI}$ positive, subtracting the percentage of PI positive cells from the healthy donors from each sample. For anti-histone treatments, patient sera were preincubated for $10 \mathrm{mins}$ with anti-histone single-chain variable fragment (ahscFv; $200 \mu \mathrm{g} / \mathrm{ml}$, synthesis described previously (18)) or with non-anticoagulant $\mathrm{N}$-acetyl heparin $(200 \mu \mathrm{g} / \mathrm{ml}$; Sigma).

Transmembrane permeability of confluent HBMEC was analysed in a dual-chamber system (0.4 $\mu \mathrm{M}$ pore size; Millipore). HBMEC were treated with normal serum or patient serum (diluted 1:1 with PBS) for 1hr, replaced with horse radish peroxidase (HRP)-containing media. 
Leaked HRP over $1 \mathrm{hr}$ was determined using TMB substrate (ThermoFisher) on a microplate reader $(450 \mathrm{~nm})$. Permeability was expressed as a fold change compared to monolayers treated with pooled normal serum from healthy UK donors [RETH000685].

Biological replicates were defined as independent experiments on primary HBMEC, treated with independently purified batches of purified histones or with serum from different patients. We generally used 3 biological replicates for experiments, based on routine practice for in vitro assays. For the 0 and $75 \mathrm{ug} / \mathrm{ml}$ of purified histones and for the healthy control and CM patients with high histones we performed 6 and 7 biological replicates. Additional replicates were as controls for comparison with the anti-histone ScFv, heparin and CM-low groups; the comparison with the other groups was similar to that presented and was significant after the initial 3 replicates.

\section{In vitro platelet aggregation}

Platelets $\left(2 \times 10^{3} / \mu \mathrm{l}\right)$ prepared from healthy donors were mixed with pooled plasma spiked with malarial histones. Platelet aggregation was determined optically at $405 \mathrm{~nm}$ (Multiskan Spectrum plate reader, ThermoScientific) in a 96-well plate, over $15 \mathrm{mins}$ at $37^{\circ} \mathrm{C}$. To normalize for differences in optical density between plasma samples each sample was blanked with plasma in the absence of platelets, allowing the specific changes in optical density induced by platelet aggregation to be determined.

\section{Statistical analysis}

Statistical analyses were performed using Stata (version 11; Statacorp) and Prism (version 8; GraphPad) software. Continuous variables were assumed to have normal or log normal distribution depending on their level of skewness. Differences between groups were compared using linear regression models. To adjust for multiple comparisons we used the Tukey (when comparing all groups to each other) or Dunnett tests (when comparing all groups to a control group). The association between histone levels and other variables was assessed by linear regression and expressed as correlation coefficients. For ordered categorical slide scoring data, the associations between histological classification, extent of sequestration and degree of fibrinogen extravasation were assessed by use of ordinal logistic regression models, controlling for clustering within cases and adjusting for any differences between scorers. All tests were two-tailed with a conventional $5 \%$ alpha-level.

\section{Results}

Circulating concentrations of extracellular histones are elevated in cerebral malaria cases and levels correlate with the degree of fibrin generation and with endothelial activation Clinical characteristics of the patients are detailed in Table 1. Compared with CM-pos, CMneg patients had a higher haemoglobin and platelet count and lower lactate level and parasite count. To explore whether histones are released in vivo and whether levels were associated 
with diagnosis, we measured circulating histones in serum samples taken from patients on admission. Histone concentrations were markedly higher in children with CM-pos than in children with $\mathrm{CM}-\mathrm{neg}$, non-CM encephalopathy, uncomplicated malaria, non-severe febrile illness or healthy controls (Fig 1A). These differences were not explained merely by an association with parasite density as there was only weak correlation between extracellular histone levels and peripheral parasite density $(r=0.22 p=0.0044$, Fig $1 B)$ and there was no correlation between histone and histidine rich protein 2 levels (PfHRP2, a released parasite protein used as a marker of biomass $[r=0.09, p=0.25]$ ).

To explore histones as a possible trigger for coagulation activation in $\mathrm{CM}$ we assessed the association between circulating histones and markers of in vivo fibrin formation and coagulation activation (11). In CM-pos cases, plasma fibrin monomer concentrations correlated with circulating histone levels $(r=0.56 ; p=<0.001$, Fig $1 C)$ more strongly than with (log) peripheral parasite density $(r=0.34, p=<0.001)$, PfHRP2 $(r=0.24, p=0.013)$, platelets $(r=-$ $0.18, p=0.2)$, lactate $(r=0.33, p=<0.001)$, blood glucose $(r=0.08 p=0.58)$ or haemoglobin $(r=0.06, p=0.89)$. Circulating histone levels showed a moderate correlation with prothrombin fragment $F 1+2$ (a marker of thrombin generation ( $r=0.34, p=<0.001$; Fig 1D)). Hence circulating histones better predict fibrin generation and coagulation activation than parasite density or other markers of disease severity.

Histones cause Weibel Palade Body (WBP) exocytosis and thrombocytopenia in mice through endothelial activation and increased platelet adhesion (25). Here circulating histone concentration correlated negatively with platelet levels, weakly in the subgroup of children with retinopathy positive $\mathrm{CM}(r=-0.22, \mathrm{p}=0.0039$ [in whom thrombocytopenia was nearly universal]), but moderately when patients with retinopathy negative $\mathrm{CM}$ were also considered ( $r=-0.41, p=<0.001 ;$ Fig 1E). Endothelial activation and WPB exocytosis are well established in $\mathrm{CM}$ including release of osteoprotegrin (OPG), which we have previously shown correlates with thrombocytopenia (40). Here circulating histone concentration correlated with plasma osteoprotegrin concentration $(r=0.54, p<0.001$, Fig $1 F)$. These data show a specific association between histones and CM-pos but not with CM-neg or aparasitaemic encephalopathy and suggest a link between extracellular histones and critical factors involved in clot formation and localization.

\section{Association between histone levels, brain swelling and fatal outcome.}

Given this association between histones and coagulopathy, a process implicated in brain swelling $(41)$ and death $(8,42)$ in $\mathrm{CM}$, we assessed the correlation between histone levels and fatal outcome and brain swelling. In children with CM-pos, the serum histone concentration was significantly higher in patients who died $(n=24$; geometric mean $35.7 \mu \mathrm{g} / \mathrm{ml}$ [18.6-68.6 $\mu \mathrm{g} / \mathrm{ml}$; Fig $2 \mathrm{~A}$ ) than in patients who survived $(\mathrm{n}=146$; geometric mean $21.6 \mu \mathrm{g} / \mathrm{ml}[16.4-$ $28.6 \mu \mathrm{g} / \mathrm{ml}$; $\mathrm{p}=0.04)$. 
In CM-pos cases histone levels were 3 times higher in children who had moderate brain swelling (geometric mean $26.9 \mu \mathrm{g} / \mathrm{ml}$; $95 \% \mathrm{Cl} 17.45-41.42, \mathrm{p}=0.031$ ) or severe brain swelling $(29.86 \mu \mathrm{g} / \mathrm{ml} ; 95 \% \mathrm{Cl} 18.58-47.97, \mathrm{p}=0.024)$ than in children who had no evidence of brain swelling on MRI $(8.79 \mu \mathrm{g} / \mathrm{ml} ; 95 \% \mathrm{Cl} 3.09-25.01)$ (Fig $2 \mathrm{~B})$. In comparison peripheral parasite density, PfHRP2, lactate, platelet levels, and osteoprotegrin levels were not significantly associated with brain swelling (Fig.S1). There was a significant association between platelet levels and swelling and lactate levels and swelling when a less stringent definition of CM was used (i.e. when both CM-pos and CM-neg cases were included, Figure S2), this wider inclusion also increased the strength of association for histones (Figure S2). Taken together these data indicate a strong association between histone levels and the degree of brain swelling over and above other laboratory factors associated with severity in CM.

Detection of significant levels of $P$. falciparum histones in patient samples using mass spectrometry

Owing to the highly conserved nature of histones, with $>90 \%$ sequence homology between Plasmodium and human histones, available antibodies react with both human and Plasmodium histones (28). We developed a semi-quantitative mass spectrometry method (outlined in Figure $3 \mathrm{~A}$ ), to determine the proportion of parasitic and human histones within patient samples. Using $P$. falciparum histones purified from culture (Fig. S3), and pure human histones, we identified specific peptides for both H4 (Fig. 3B, C, Fig. S4) and H2A.Z (Fig. S4) that distinguished between $P$. falciparum and human histones (Fig. 3D, E). We then applied this method to serum samples from 10 children with CM-pos. P. falciparum and human histones were identified in all $10 \mathrm{CM}$ cases, with $P$. falciparum histones constituting a mean of $51 \%$ (range $2 \%$ to $91 \%$, Fig. $3 \mathrm{~F}, \mathrm{G}$ ) of the total histone concentration.

Accumulation of histones at the endothelial surface in the brain in fatal cases is associated with sequestration and with blood brain barrier breakdown

Histone mediated barrier disruption is caused by histones binding to the endothelium, observed by histology in histone-infused mice (22). To explore whether extracellular histones bind to the endothelium in $\mathrm{CM}$ we performed immunostaining for histones in post-mortem brain samples from Malawian children (details of cases in Table S1). Compared with "faux $\mathrm{CM}^{\prime \prime}(\mathrm{CM} 3)$ cases ( $n=6$, Fig $4 A$ ) or non-CM cases $(n=5)$ luminal histone staining was more frequent and stronger in $\mathrm{CM}$ cases $(\mathrm{CM} 1 / 2, \mathrm{n}=15$, Fig $4 \mathrm{~B})$. Quantifying this by scoring with observers blinded to diagnosis, strong membrane staining was markedly associated with definitive $\mathrm{CM}$ when compared with faux $\mathrm{CM}$ (odds ratio [OR] 2.6; 95\% Confidence Interval [CI] 1.7 - 3.9; $p<0.001$ ) or non-CM (OR 7.2; 95\% Cl 5.0 - 10.6; $p<0.001$; Fig 4C).

Among definitive $\mathrm{CM}$ cases there was a strong association between histone membrane 
staining being present was $5.2(95 \% \mathrm{Cl} 2.8-9.7, \mathrm{p}<0.001$; Fig 4D); when greater than $50 \%$ of the vessel contained sequestered IE (++) the OR for the presence of histone staining was 16.9 (95\% Cl $9.2-31.3 ; p<0.001)$.

Histone staining was also strongly correlated with areas of BBB breakdown, demonstrated by staining for fibrinogen extravasation (Fig 4E): weak histone staining was associated with an OR of 2.8 for the presence of fibrinogen extravasation ( $95 \% \mathrm{Cl} 1.6-5.0 ; p=<0.001,4 \mathrm{~F}$ ) and strong histone staining with an OR of 4.5 for fibrinogen extravasation ( $95 \% \mathrm{Cl} 1.8-11.4$; $\mathrm{p}=0.001$ ), as shown in fig. $4 \mathrm{H}$ as "\% of vessels with leak". Histone staining was also observed to co-localize with thrombi (Fig 4G) and with ring hemorrhages (Fig $4 \mathrm{H}$ ).

Purified P. falciparum histones and serum from CM cases induce endothelial damage and barrier disruption

Mammalian histones directly induce endothelial cell membrane damage and barrier disruption on human vein umbilical vein $\mathrm{EC}(16,18)$ and $P$. falciparum histones induce damage in dermal and lung EC (28). To investigate the potential relevance of this in the brain, we tested whether purified $P$. falciparum histones cause cell damage and leak on primary human brain microvascular EC (HBMEC). P. falciparum histones induced significant cellular toxicity (Fig. 5A, B) similar to the effects seen with mammalian histones $(16,18)$. To demonstrate that this effect was specifically induced by histones, and not a contaminant, we used an antihistone single-chain Fragment variable (ahscFv), previously shown to inhibit histone toxicity $(18,43)$. ahscFV abrogated histone-induced toxicity (Fig. 5A). Non-anti-coagulant heparin, a potential treatment with minimal toxicity that prevents toxicity of mammalian histones (24), also prevented $P$. falciparum histone toxicity on HBMEC (Fig. 5A).

To investigate whether circulating histones from patients induce membrane toxicity, we incubated patient serum with HBMEC. Serum from CM-pos cases with elevated histones (histone concentration $>100 \mathrm{ug} / \mathrm{ml}$; Fig $5 \mathrm{~B} ; \mathrm{n}=3$ ) induced significant cellular toxicity, whereas serum from $\mathrm{CM}$-pos cases without substantially elevated histones levels (histone concentration $<25 \mathrm{ug} / \mathrm{ml} ; \mathrm{n}=3$ ) did not, nor did samples from children with uncomplicated malaria $(n=3)$, mild non-malarial febrile illness $(n=3)$, non-malarial encephalopathy $(n=3)$ or retinopathy negative $\mathrm{CM}(n=3$; Figure $5 B)$. Serum-induced toxicity was abrogated by ahscFv treatment, supporting a causal link with histones in the serum (Fig. 5A, B).

We next investigated the effect of purified $P$. falciparum histones and patient serum on barrier integrity. Similar to human histones, $P$. falciparum histones induced rapid barrier disruption in HBMEC. This leak was reversed by ahscFv (Fig S5). Similarly, serum from CM-pos cases with high histone levels $(n=3)$ induced leak, but serum from CM-neg cases and other control groups (all $n=3$ ) did not. Leak in the CM-pos cases was abrogated by ahscFV, also supporting that histones in the serum were causal in this leak (Fig. 5C). 
Given the correlation between histones and thrombocytopenia in CM (Fig. 1E) we investigated whether $P$. falciparum histones also cause platelet aggregation. Incubation of purified $P$. falciparum histones with platelet rich plasma from normal healthy controls resulted in dose dependent platelet aggregation, inhibited with ahscFv treatment (Fig. 5D).

460

\section{Discussion}

462 A number of factors released from IE have been shown to cause endothelial damage or leak in vitro including glycosylphosphatidylinositol (44), extracellular vesicles (45), hemozoin and PfHRP2. IE-EC receptor-ligand interactions also cause endothelial perturbation (46-48). While it seems likely that $\mathrm{CM}$ pathogenesis constitutes a combination of interacting factors, rather than a single toxin or ligand $(49,50)$, we sought a factor that is necessary for CM vascular pathology and targetable with a safe and deployable treatment. Histones were a compelling candidate. Firstly because of the strong parallels between the clinicopathological features of histone-induced vascular pathology in other conditions and those in malaria. Secondly, because the sequestration of histone-packed IE in tissues would predict substantial concentration of histones being extruded to the endothelial surface. Thirdly because histones are a plausible target for an adjunctive therapy; treatments targeted against histones are protective in animal models of sepsis and trauma, even though extracellular histones are clearly not the sole factor contributing to pathogenesis in either of these conditions.

Our data provide evidence for histones as a mediator of the vascular pathology in the brain in $\mathrm{CM}$ that link causal data from ex vivo experiments (patient serum directly causes leak and toxicity, which is reversed by blocking histones) to multi-model observations in a rigorously defined patient cohort. Correlation between histones levels, diagnosis, fatal outcome, thrombocytopenia and fibrin production imply a role for histones in death and in key pathogenetic processes. Employing MRI scans and a grading system we established a correlation between serum histone levels and the level of brain swelling in children. We then showed that a significant proportion of histones were of parasite origin. Although human histones are also toxic, they are produced by diverse activated or damaged cells and might be a bystander event, triggered distant from sites of sequestration and vascular pathology. In contrast, parasite histones in the systemic circulation strongly suggest downstream detection of histones released from rupturing mature schizonts, in which histones are concentrated 1624-fold, occurring almost exclusively in sequestered IE. Examination of histological staining in post-mortem CM brain samples supported this paradigm. Extracellular histones were bound to the $\mathrm{EC}$ membrane, more frequently in $\mathrm{CM}$ cases than controls and spatially associated with the presence of sequestered IE and with areas of fibrinogen leak and thrombosis. purified $P$. falciparum histones from parasites grown in culture and showed that they induced 
cases with high levels of histones also induced EC membrane toxicity and leak. Both were blocked by pre-incubation with ahscFv, indicating that the effects were caused by active histones in serum. Heparins, including non-anticoagulant heparins have been shown to neutralize the effects of mammalian histones and may represent promising therapies. As a proof of concept, we showed that non-anticoagulant heparin prevented toxicity from $P$. falciparum histones. Taken together, these data show that $P$. falciparum histones are produced at significant levels in vivo, that they circulate in an active form, show a causal role for histones from patient serum samples ex vivo in processes leading to $\mathrm{CM}$ pathogenesis and provide multiple points of evidence supporting a role of histones in key disease processes in patients.

The locations of plasmodial histone production and what we know about modifiers of histone response fit well with the non-uniform pattern of vascular involvement in $\mathrm{CM}$, whereby coagulopathy and leak are localized to sites of IE sequestration and in particular to the brain. It is notable that the median concentration of histones in the serum in CM-pos cases was $24.6 \mu \mathrm{g} / \mathrm{ml}$, and that toxicity to HBMEC in our assay was only seen at histones concentrations of $>50 \mu \mathrm{g} / \mathrm{ml}$ (similar to mammalian histones and to experiments using purified exogenous histone infusion in mice $(16,22,28)$ ). The implication being that in most patients with $\mathrm{CM}$, histone levels in the circulation do not reach levels sufficient to cause systemic toxicity. This is in keeping with the observed clinical pattern of disease in CM in African children: deep coma and marked cerebral irritability, generally without multi-organ failure (14) or systemic coagulopathy (11). In contrast it seems highly plausible that $P$. falciparum histones concentrate several-fold at sites of intense sequestration (Fig. 3B) and cross this toxic threshold. We hypothesize that the brain is particularly vulnerable to histone toxicity because of reduced capacity to produce aPC. This would not be expected to manifest in conditions involving release of histones from immune-activated cells such as in sepsis and trauma, given that the brain is an immune-privileged site (51). The paradigm in CM is different; parasite histones reach high levels in the brain through IE sequestration. Moreover, IE sequestration in the brain may itself impair aPC production - firstly because IE reduce surface thrombomodulin and EPCR, putatively by receptor cleavage $(8,15)$. Secondly, parasite variants associated with the development of $\mathrm{CM}$ (expressing domain cassette 8 [DC8]) reduce aPC production, by binding to EPCR and inhibiting its activity (52). DC8 variants also show a tropism for brain endothelium $(34,52,53)$. Hence parasites in CM patients may be more likely to concentrate plasmodial histones in the brain, through sequestration, and simultaneously may prevent their breakdown, through inhibiting aPC production. In support of this, DC8 expressing variants are associated with both thrombocytopenia and brain swelling (48); aPC inhibition potentially increasing both histone-induced platelet aggregation and histoneinduced endothelial leak. It is notable that histones are implicated in neurotoxicity and ischemic damage in neurodegenerative conditions and stroke, and that in animal models these effects are reversed by aPC (54-56). 
Our study has several limitations. Firstly, our study is in human patients. While generally a strength, this leads to marked heterogeneity, including in variables that might affect histone levels, such as length of illness and timing of antimalarial administration. Further we took blood from each patient at only one timepoint, representing a snapshot in a dynamic disease process. This precluded examination of the temporal association between histone levels and other variables. Secondly, while the association between histone binding and sequestration and the finding that $51 \%$ of histones in serum were of parasite origin are both highly suggestive of a parasite origin for luminal histones, we did not prove this. Nonetheless concentration of host histones at sites of IE sequestration would also be predicted to have similar effects and to respond to similar treatments.

Given that a significant proportion of histones detected in blood are of parasite origin it is notable that histone levels do not correlate well with parasitemia or PfHRP2. This may reflect the limitations of each of these assays, used at a single time point, to determine total parasite biomass. Firstly, our main assay to determine histone levels does not distinguish human from parasite histones. Serum histone levels are likely to be a function of production, breakdown and luminal binding and hence it is unclear how accurately serum histone levels of either species correlate with total production. Secondly peripheral parasitemia is a poor predictor of total parasite biomass: sequestered IE do not circulate, and so the concentration of parasites detectable in the periphery fluctuates markedly depending on the stage of the majority of the parasites in an individual patient. Thirdly, PfHRP2, a soluble parasite factor, has a long half-life and therefore its concentration in serum is a function of parasite biomass and duration of infection. While PfHRP2 is a predictor of parasite biomass and correlates with disease severity in several populations $(57,58)$, among Malawian children with $\mathrm{CM}$, serum PfHRP2 levels do not correlate well with markers of severity (such as lactate or thrombocytopenia) or with outcome (59).

Further work is warranted to explore the biology and timing of plasmodial histone release and the mechanism of action of plasmodial histones in greater detail. A specific antibody against $P$. falciparum histone would be useful to differentiate $P$. falciparum histone levels in serum and in tissue. It remains to be determined whether agents that neutralize or degrade histones can reduce brain swelling during the critical 24 hours after hospital admission and thereby improve outcome in CM. Potential agents include aPC or heparin $(24,60,61)$. Modified non-anticoagulant heparins are a rational first choice, particularly given their use in critically ill patients with a variety of inflammatory diseases (61) and in patients with sickle cell crisis (62). There is a planned phase II study in patients to use a modified heparin to reverse binding and rosetting in malaria. A different dosing regimen is likely to be needed to reverse the effects of histones than to block binding, which would require further investigation. However, the possibility that modified heparins could be synergistic in malaria - both reducing binding and neutralizing heparins - make the potential benefits more 
compelling. Finally, since cells in all eukaryotic organisms contain histones it will be important to explore whether parasite histones contribute to pathogenesis in other parasitic infections.

\section{Supplementary Materials}

Fig. S1. Histones but not other laboratory factors are associated with the degree of brain swelling in CM-pos patients.

Fig. S2. When both CM-pos and CM-neg cases are included, histones platelet count and lactate are associated with the degree of brain swelling.

Fig. S3. Gel showing purified Plasmodium falciparum (P. f.) and human histones.

Fig. S4. Alignment of Homo sapiens and $P$. falciparum histones

Fig. S5. Time-course of barrier disruption of Primary human brain microvascular endothelial cells (HBMEC) by $P$. falciparum histones in a dual chamber system

Table S1. Summary of post-mortem cases

\section{References}

1. Taylor TE, Fu WJ, Carr RA, Whitten RO, Mueller JS, Fosiko NG, et al. Differentiating the pathologies of cerebral malaria by postmortem parasite counts. Nat Med. 2004;10(2):143-5.

2. WHO. World Malaria Report 2017. Geneva: World Health Organization; 20172017. 3. Seydel KB, Kampondeni SD, Valim C, Potchen MJ, Milner DA, Muwalo FW, et al. Brain swelling and death in children with cerebral malaria. The New England journal of medicine. 2015;372(12):1126-37.

4. Mohanty S, Benjamin LA, Majhi M, Panda P, Kampondeni S, Sahu PK, et al. Magnetic Resonance Imaging of Cerebral Malaria Patients Reveals Distinct Pathogenetic Processes in Different Parts of the Brain. mSphere. 2017;2(3).

5. Dondorp AM, Fanello Cl, Hendriksen IC, Gomes E, Seni A, Chhaganlal KD, et al. Artesunate versus quinine in the treatment of severe falciparum malaria in African children (AQUAMAT): an open-label, randomised trial. Lancet. 2010;376(9753):1647-57.

6. Barrera V, MacCormick IJC, Czanner G, Hiscott PS, White VA, Craig AG, et al. Neurovascular sequestration in paediatric $P$. falciparum malaria is visible clinically in the retina. Elife. 2018;7.

7. Zhao Y, MacCormick IJ, Parry DG, Leach S, Beare NA, Harding SP, et al. Automated detection of leakage in fluorescein angiography images with application to malarial retinopathy. Sci Rep. 2015;5:10425.

8. Moxon CA, Wassmer SC, Milner DA, Jr., Chisala NV, Taylor TE, Seydel KB, et al. Loss of endothelial protein $C$ receptors links coagulation and inflammation to parasite sequestration in cerebral malaria in African children. Blood. 2013;122(5):842-51. 9. Dorovini-Zis K, Schmidt K, Huynh H, Fu W, Whitten RO, Milner D, et al. The neuropathology of fatal cerebral malaria in malawian children. Am J Pathol. 2011;178(5):2146-58.

10. Francischetti IM, Seydel KB, Monteiro RQ, Whitten RO, Erexson CR, Noronha AL, et al. Plasmodium falciparum-infected erythrocytes induce tissue factor expression in endothelial cells and support the assembly of multimolecular coagulation complexes. J Thromb Haemost. 2007;5(1):155-65. 
11. Moxon CA, Chisala NV, Mzikamanda R, MacCormick I, Harding S, Downey C, et al. Laboratory evidence of disseminated intravascular coagulation is associated with a fatal outcome in children with cerebral malaria despite an absence of clinically evident thrombosis or bleeding. J Thromb Haemost. 2015;13(9):1653-64.

628 12. Greiner J, Dorovini-Zis K, Taylor TE, Molyneux ME, Beare NA, Kamiza S, et al. Correlation of hemorrhage, axonal damage, and blood-tissue barrier disruption in brain and retina of Malawian children with fatal cerebral malaria. Front Cell Infect Microbiol. 2015;5:18.

632 13. Haldar K, Murphy SC, Milner DA, Taylor TE. Malaria: mechanisms of erythrocytic infection and pathological correlates of severe disease. Annu Rev Pathol. 2007;2:217-49. 14. Milner DA, Jr., Whitten RO, Kamiza S, Carr R, Liomba G, Dzamalala C, et al. The systemic pathology of cerebral malaria in African children. Front Cell Infect Microbiol. 2014;4:104.

637

638 15. Aird WC, Mosnier LO, Fairhurst RM. Plasmodium falciparum picks (on) EPCR. Blood. 2013. 16. Xu J, Zhang X, Pelayo R, Monestier M, Ammollo CT, Semeraro F, et al. Extracellular histones are major mediators of death in sepsis. Nature medicine. 2009;15(11):1318-21.

641 17. Szatmary P, Huang W, Criddle D, Tepikin A, Sutton R. Biology, role and therapeutic potential of circulating histones in acute inflammatory disorders. J Cell Mol Med. 2018;22(10):4617-29. mediators of trauma-associated lung injury. Am J Respir Crit Care Med. 2013;187(2):160-9. 19. Alhamdi Y, Abrams ST, Lane S, Wang G, Toh CH. Histone-Associated Thrombocytopenia in Patients Who Are Critically III. JAMA. 2016;315(8):817-9. 20. Alhamdi Y, Abrams ST, Cheng Z, Jing S, Su D, Liu Z, et al. Circulating Histones Are Major Mediators of Cardiac Injury in Patients With Sepsis. Crit Care Med. 2015;43(10):2094103. 21. Abrams ST, Zhang N, Dart C, Wang SS, Thachil J, Guan Y, et al. Human CRP defends against the toxicity of circulating histones. J Immunol. 2013;191(5):2495-502. mediators of trauma-associated lung injury. American journal of respiratory and critical care medicine. 2013;187(2):160-9. Concentrations Differentially Affect the Predominance of Left or Right Ventricular Dysfunction in Critical Illness. Crit Care Med. 2015.

659 24. Wildhagen KC, Garcia de Frutos P, Reutelingsperger CP, Schrijver R, Areste C, OrtegaGomez A, et al. Nonanticoagulant heparin prevents histone-mediated cytotoxicity in vitro and improves survival in sepsis. Blood. 2014;123(7):1098-101. inflammation and thrombosis through the induction of Weibel-Palade body exocytosis. J Thromb Haemost. 2016;14(11):2274-86. in vascular endothelial cells via TLR and activation of NF-kappaB and AP-1. Thromb Res. 2016;137:211-8.

668 27. Kim JE, Yoo HJ, Gu JY, Kim HK. Histones Induce the Procoagulant Phenotype of 669 Endothelial Cells through Tissue Factor Up-Regulation and Thrombomodulin DownRegulation. PLoS One. 2016;11(6):e0156763. 
671

672

673

674

675

676

677

678

679

680

681

682

683

684

685

686

687

688

689

690

691

692

693

694

695

696

697

698

699

700

701

702

703

704

705

706

707

708

709

710

711

712

713

714

715

28. Gillrie MR, Lee K, Gowda DC, Davis SP, Monestier M, Cui L, et al. Plasmodium falciparum histones induce endothelial proinflammatory response and barrier dysfunction. The American journal of pathology. 2012;180(3):1028-39.

29. Seydel KB, Milner DA, Jr., Kamiza SB, Molyneux ME, Taylor TE. The distribution and intensity of parasite sequestration in comatose Malawian children. J Infect Dis. 2006;194(2):208-5.

30. Turner GD, Morrison H, Jones M, Davis TM, Looareesuwan S, Buley ID, et al. An immunohistochemical study of the pathology of fatal malaria. Evidence for widespread endothelial activation and a potential role for intercellular adhesion molecule- 1 in cerebral sequestration. Am J Pathol. 1994;145(5):1057-69.

31. Macko RF, Killewich LA, Fernandez JA, Cox DK, Gruber A, Griffin JH. Brain-specific protein $C$ activation during carotid artery occlusion in humans. Stroke; a journal of cerebral circulation. 1999;30(3):542-5.

32. Ishii H, Salem HH, Bell CE, Laposata EA, Majerus PW. Thrombomodulin, an endothelial anticoagulant protein, is absent from the human brain. Blood. 1986;67(2):362-5. 33. Laszik Z, Mitro A, Taylor FB, Jr., Ferrell G, Esmon CT. Human protein C receptor is present primarily on endothelium of large blood vessels: implications for the control of the protein C pathway. Circulation. 1997;96(10):3633-40.

34. Claessens A, Adams Y, Ghumra A, Lindergard G, Buchan CC, Andisi C, et al. A subset of group $A$-like var genes encodes the malaria parasite ligands for binding to human brain endothelial cells. Proc Natl Acad Sci U S A. 2012;109(26):E1772-81.

35. Turner L, Lavstsen T, Berger SS, Wang CW, Petersen JE, Avril M, et al. Severe malaria is associated with parasite binding to endothelial protein $C$ receptor. Nature. 2013;498(7455):502-5.

36. Petersen JE, Bouwens EA, Tamayo I, Turner L, Wang CW, Stins M, et al. Protein C system defects inflicted by the malaria parasite protein PfEMP1 can be overcome by a soluble EPCR variant. Thromb Haemost. 2015;114(5):1038-48.

37. Barrera V, Hiscott PS, Craig AG, White VA, Milner DA, Beare NA, et al. Severity of Retinopathy Parallels the Degree of Parasite Sequestration in the Eyes and Brains of Malawian Children With Fatal Cerebral Malaria. The Journal of infectious diseases. 2014. 38. Small DS, Taylor TE, Postels DG, Beare NA, Cheng J, MacCormick IJ, et al. Evidence from a natural experiment that malaria parasitemia is pathogenic in retinopathy-negative cerebral malaria. Elife. 2017;6.

39. Liaw PC, Fredenburgh JC, Stafford AR, Tulinsky A, Austin RC, Weitz JI. Localization of the thrombin-binding domain on prothrombin fragment 2 . The Journal of biological chemistry. 1998;273(15):8932-9.

40. O'Regan N, Moxon C, Gegenbauer K, O'Sullivan JM, Chion A, Smith OP, et al. Marked elevation in plasma osteoprotegerin constitutes an early and consistent feature of cerebral malaria. Thromb Haemost. 2016;115(4):773-80.

41. Potchen MJ, Kampondeni SD, Seydel KB, Haacke EM, Sinyangwe SS, Mwenechanya $M$, et al. 1.5 Tesla Magnetic Resonance Imaging to Investigate Potential Etiologies of Brain Swelling in Pediatric Cerebral Malaria. Am J Trop Med Hyg. 2018;98(2):497-504.

42. Moxon CA, Zhao L, Li C, Seydel KB, MacCormick IJ, Diggle PJ, et al. Safety of lumbar puncture in comatose children with clinical features of cerebral malaria. Neurology. 2016;87(22):2355-62. 
43. Dou Y, Mizzen CA, Abrams M, Allis CD, Gorovsky MA. Phosphorylation of linker histone $\mathrm{H} 1$ regulates gene expression in vivo by mimicking $\mathrm{H} 1$ removal. Mol Cell. 1999;4(4):641-7.

\section{Schofield L, Vivas L, Hackett F, Gerold P, Schwarz RT, Tachado S. Neutralizing} monoclonal antibodies to glycosylphosphatidylinositol, the dominant TNF-alpha-inducing toxin of Plasmodium falciparum: prospects for the immunotherapy of severe malaria. Ann Trop Med Parasitol. 1993;87(6):617-26.

45. Mantel PY, Hoang AN, Goldowitz I, Potashnikova D, Hamza B, Vorobjev I, et al. Malaria-infected erythrocyte-derived microvesicles mediate cellular communication within the parasite population and with the host immune system. Cell Host Microbe. 2013;13(5):521-34.

46. Chakravorty SJ, Hughes KR, Craig AG. Host response to cytoadherence in Plasmodium falciparum. Biochem Soc Trans. 2008;36(Pt 2):221-8.

47. Tripathi AK, Sullivan DJ, Stins MF. Plasmodium falciparum-infected erythrocytes increase intercellular adhesion molecule 1 expression on brain endothelium through NFkappaB. Infection and immunity. 2006;74(6):3262-70.

48. Kessler A, Dankwa S, Bernabeu M, Harawa V, Danziger SA, Duffy F, et al. Linking EPCR-Binding PfEMP1 to Brain Swelling in Pediatric Cerebral Malaria. Cell Host Microbe. 2017;22(5):601-14 e5.

49. Cunnington AJ, Walther M, Riley EM. Piecing together the puzzle of severe malaria. Sci Transl Med. 2013;5(211):211ps18.

50. Miller LH, Ackerman HC, Su XZ, Wellems TE. Malaria biology and disease pathogenesis: insights for new treatments. Nature medicine. 2013;19(2):156-67. 51. Spadoni I, Fornasa G, Rescigno M. Organ-specific protection mediated by cooperation between vascular and epithelial barriers. Nat Rev Immunol. 2017;17(12):76173.

52. Turner L, Lavstsen T, Berger SS, Wang CW, Petersen JE, Avril M, et al. Severe malaria is associated with parasite binding to endothelial protein $C$ receptor. Nature. 2013.

53. Storm J, Jespersen JS, Seydel KB, Szestak T, Mbewe M, Chisala NV, et al. Cerebral malaria is associated with differential cytoadherence to brain endothelial cells. EMBO Mol Med. 2019;11(2).

54. Cheng T, Liu D, Griffin JH, Fernandez JA, Castellino F, Rosen ED, et al. Activated protein $\mathrm{C}$ blocks p53-mediated apoptosis in ischemic human brain endothelium and is neuroprotective. Nature medicine. 2003;9(3):338-42.

55. Griffin JH, Zlokovic BV, Mosnier LO. Activated protein C, protease activated receptor 1, and neuroprotection. Blood. 2018;132(2):159-69.

56. Gilthorpe JD, Oozeer F, Nash J, Calvo M, Bennett DL, Lumsden A, et al. Extracellular histone $\mathrm{H} 1$ is neurotoxic and drives a pro-inflammatory response in microglia. F1000Res. 2013;2:148.

57. Dondorp AM, Desakorn V, Pongtavornpinyo W, Sahassananda D, Silamut K, Chotivanich $\mathrm{K}$, et al. Estimation of the total parasite biomass in acute falciparum malaria from plasma PfHRP2. PLoS medicine. 2005;2(8):e204.

58. Hendriksen IC, Mwanga-Amumpaire J, von Seidlein L, Mtove G, White LJ, Olaosebikan $\mathrm{R}$, et al. Diagnosing severe falciparum malaria in parasitaemic African children: a prospective evaluation of plasma PfHRP2 measurement. PLoS medicine. 2012;9(8):e1001297. 
59. Thakur KT, Vareta J, Carson KA, Kampondeni S, Potchen MJ, Birbeck GL, et al. Cerebrospinal fluid Plasmodium falciparum histidine-rich protein-2 in pediatric cerebral malaria. Malar J. 2018;17(1):125.

60. Griffin JH, Zlokovic BV, Mosnier LO. Activated protein C: biased for translation. Blood. 2015;125(19):2898-907.

61. Cassinelli G, Naggi A. Old and new applications of non-anticoagulant heparin. Int J Cardiol. 2016;212 Suppl 1:S14-21.

62. Telen MJ, Batchvarova M, Shan S, Bovee-Geurts PH, Zennadi R, Leitgeb A, et al. Sevuparin binds to multiple adhesive ligands and reduces sickle red blood cell-induced vasoocclusion. Br J Haematol. 2016;175(5):935-48.

Acknowledgments: For recruiting and caring for patients, we would like to thank the nurses and clinicians on the Paediatric Research Ward team (Malawi-Liverpool-Wellcome Clinical Research Programme and Blantyre Malaria Project), and the nurses and clinicians in the Department of Paediatrics and Child Health (Queen Elizabeth Hospital, Blantyre, Malawi). For performing the fibrin-based assays, we would like to thank C. Powell (Roald Dahl Haemostasis \& Thrombosis Centre, Liverpool, U.K.). For histopathology advice we would like to thank Dan Milner. For technical support with histopathology we would like to thank Qian Zhen (Program in Dermatopathology, Department of Pathology, Brigham and Women's Hospital, Boston, U.S.A.). For providing laboratory space and advice we would like to thank Dyann Wirth. For helpful comments on the manuscript we would like to thank Andy Waters and Matthias Marti (Wellcome Centre for Integrative Parasitology, University of Glasgow). Funding: This work was supported by funding from the Wellcome Trust (to C.A.M; 109698/Z/15/Z) and Academy of Medical Sciences (to C.A.M.); and a grant from the NIH (T. E. Taylor, 5R01AI034969-14). The Malawi-Liverpool Wellcome Clinical Research Programme is supported by core funding from The Wellcome Trust (084679/Z/08/Z).

Author contributions: C.A.M., S.T.A., A.G.C., W.G. and C.H.T., conceived the study and designed experiments. C.A.M. and S.A. performed analysis. Y.A., S.A., J-Y. K., J.S., J.M.T., N.O. and C.A.M. performed laboratory experiments. K.B.S. and T.E.T. ran the clinical study and provided clinical and scientific input. M.E.M. provided clinical and scientific input. G.M., G.G-C. and J.O. designed experiments and provided scientific and technical input. C.A.M. wrote the original draft with significant input from A.G.C, S.A. and C.H.T. All authors contributed to critical review and editing of the manuscript.

Competing interests: The authors have no conflicting interests. 


\section{Figures}

808

A

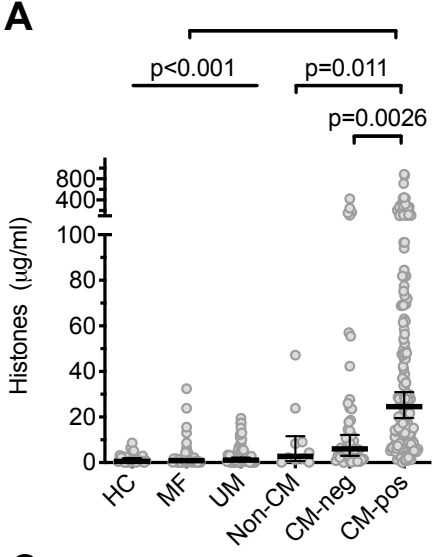

C

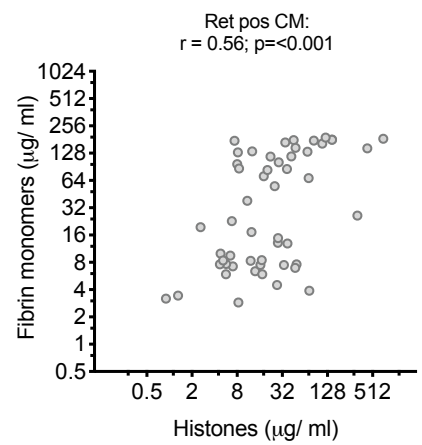

E

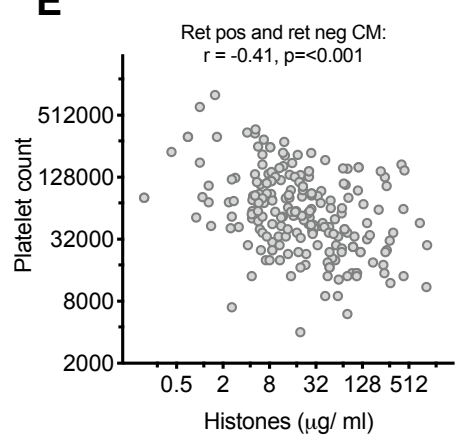

B

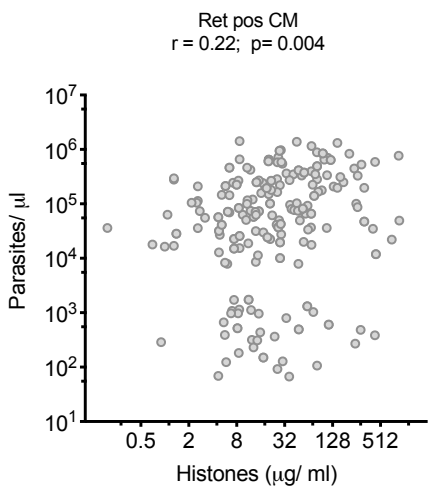

D

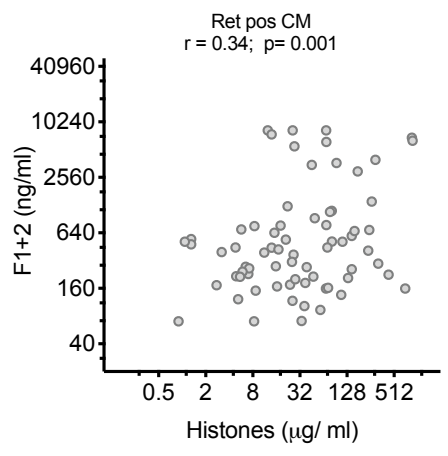

$\mathbf{F}$

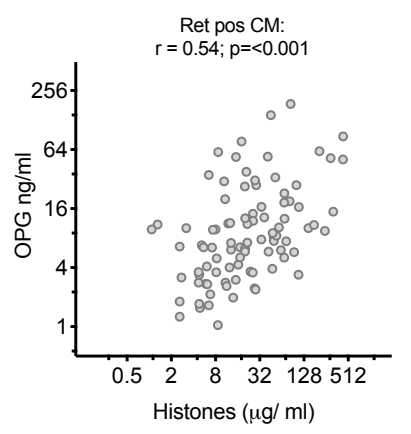

Fig 1. Circulating extracellular histones are elevated in cerebral malaria and correlate with intravascular fibrin generation and with endothelial activation. Extracellular histone levels were measured in serum samples taken on admission. (A) The mean concentration of extracellular histone levels in circulation was significantly higher in retinopathy positive cerebral malaria cases (CM-pos) than in all other patient groups including retinopathy negative $\mathrm{CM}$ (CM-neg). (B-F) correlations between serum extracellular histone concentration: peripheral parasite density in children with CM-pos (B); plasma fibrin monomer levels in children with CM-pos (C); prothrombin fragment F1+2 in children with CM-pos (D); platelet count among all children with CM (CM-pos and CM-neg) (E); plasma osteoprotegrin (OPG) concentration in children with CM-pos (F). $\mathrm{HC}=$ Healthy control; $\mathrm{MF}=$ Mild Febrile illness; $\mathrm{UM}=$ uncomplicated malaria; Non-CM (aparasitaemic children with encephalopathy [in coma] due to a cause other than malaria). 

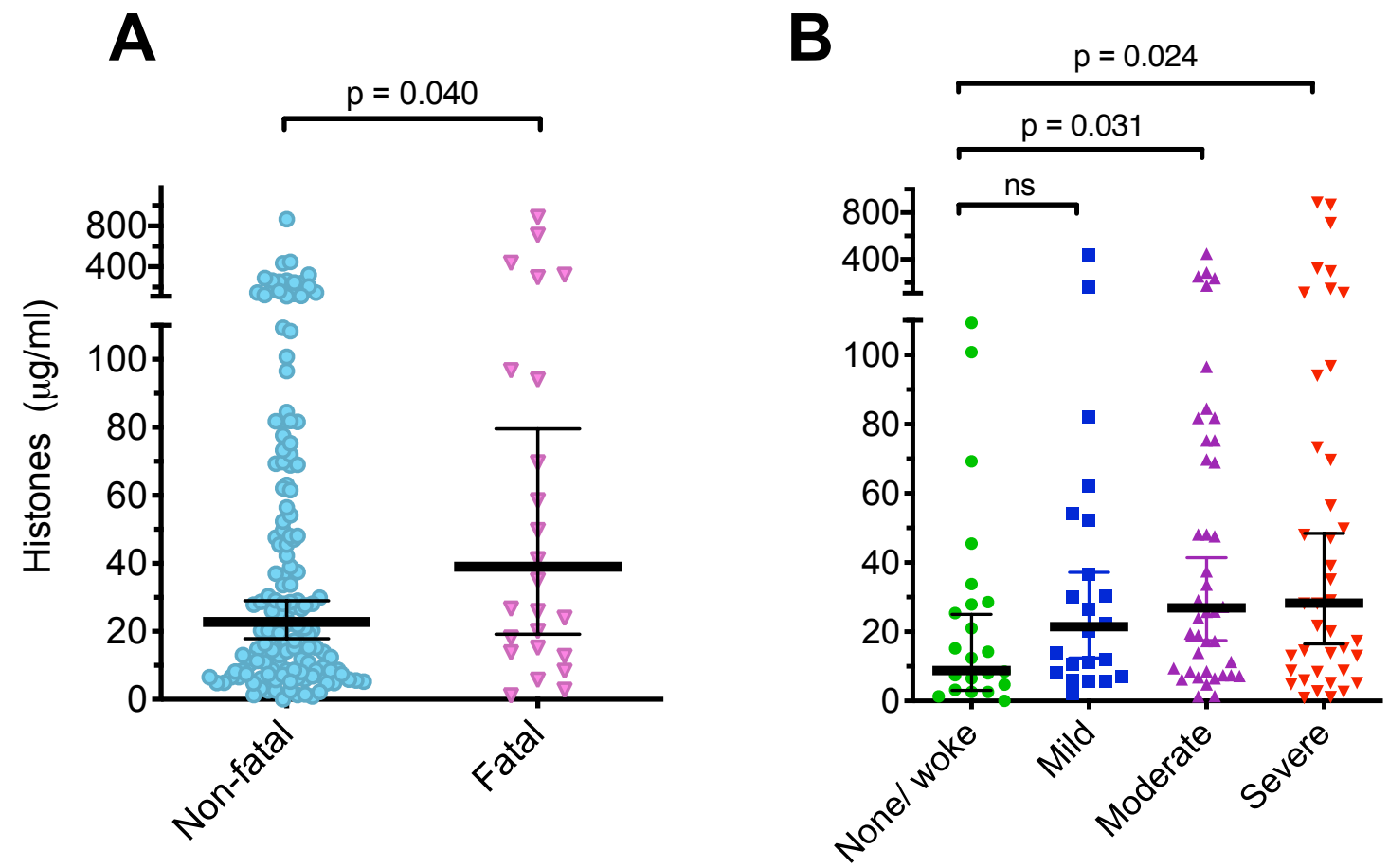

Fig 2. Extracellular histones are associated with fatal outcome and with the degree of brain swelling demonstrated on MRI scan.

828 (A) In CM-pos cases ( $n=170)$, the mean extracellular histone level was higher in children who went on to die (fatal; $n=24$ ) than in those who survived (non-fatal; $n=146$ ). (B) Children were categorised by the degree of brain swelling on MRI; circulating histones were higher in children with moderate $(n=41)$ or severe brain swelling $(n=47)$ than in those with no evidence of brain swelling $(n=22)$. 

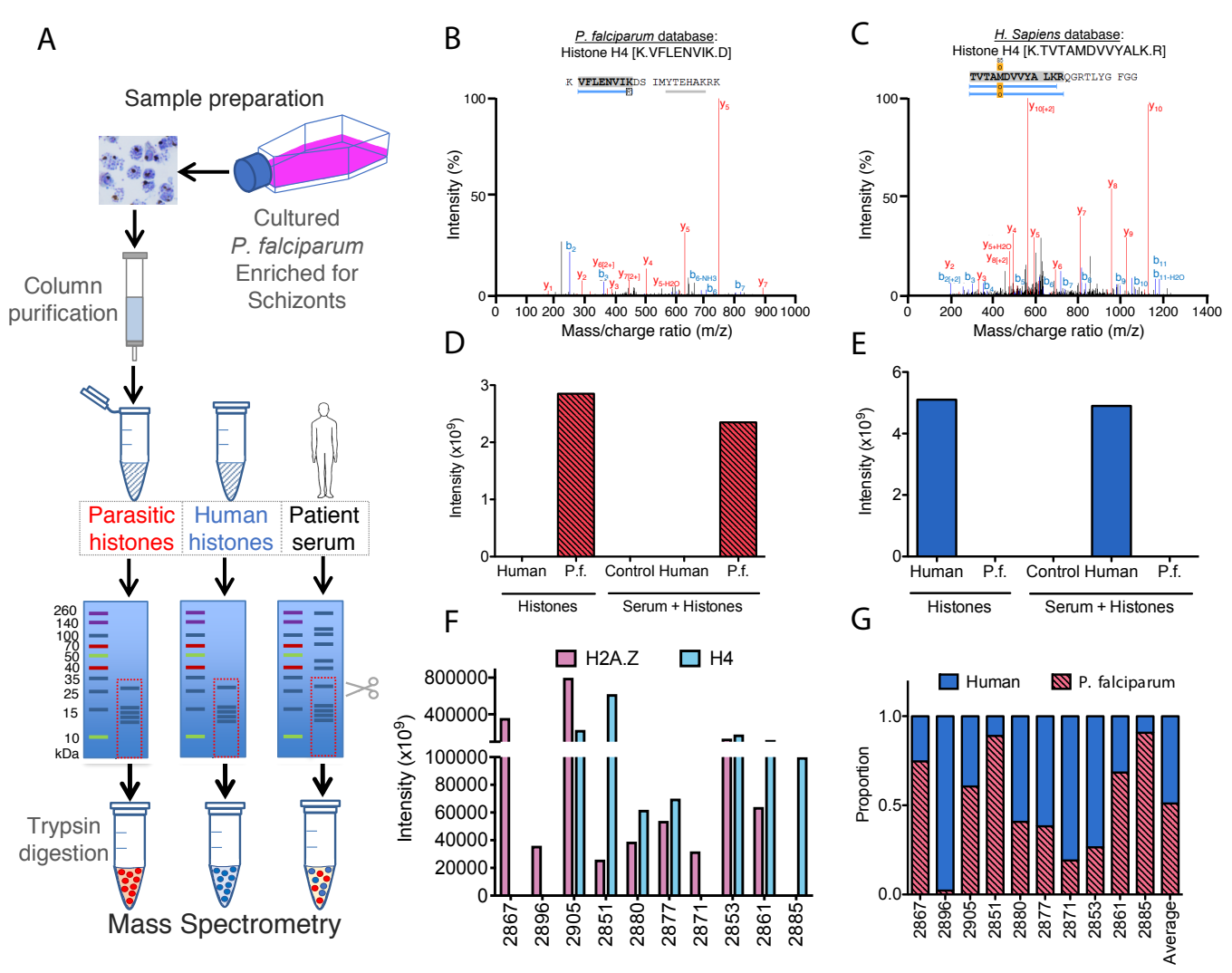

Figure 3. Mass spectrometry analysis of origin of extracellular histones in cerebral malaria cases. (A) Schematic representation of the methodology used for isolation, purification and mass spectrometry analysis. $(B, C)$ Using Skyline software and by aligning trypsin fragments to reference amino acid sequences we were able to identify specific histone H2A.Z and H4 peptides that were present in purified $P$. falciparum (malarial) preparations, that were not present in purified human histones $(\mathrm{H} 1, \mathrm{H} 2 \mathrm{~A}, \mathrm{H} 2 \mathrm{~B}, \mathrm{H} 3$ and $\mathrm{H} 4)$ and vice versa. Typical peptides are presented from human (B) and malarial (C) database searches. Using Skyline software, we were able to identify histone $\mathrm{H} 4$ peptides for each species that demonstrated different Mass/ Charge ratios with distinct human and $P$. falciparum peptides and also distinct H2A.Z human and $P$. falciparum peptides (data not shown). (D,E) This enabled us to identify with high specificity and $P$. falciparum (D) and Human (E) species-specific peptides derived from samples spiked into PBS (left) or serum (right); data shown are for H4. (F) In CM-pos patient serum ( $n=10$ ) we were able to $P$. falciparum histones H2A.Z and H4 in the samples as well as human H2A.Z and H4 (data not shown). (G) We combined the contribution of these two components to estimate the variable proportions of circulating human and $P$. falciparum in the patient serum, demonstrating a significant contribution of $P$. falciparum histones to the total pool. 


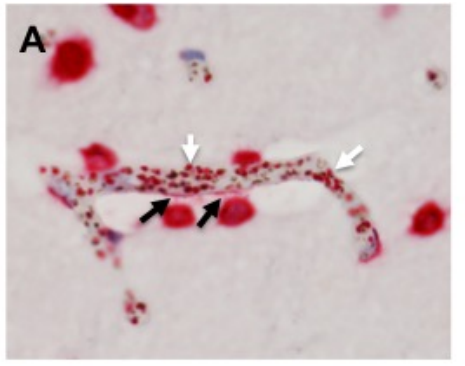

C
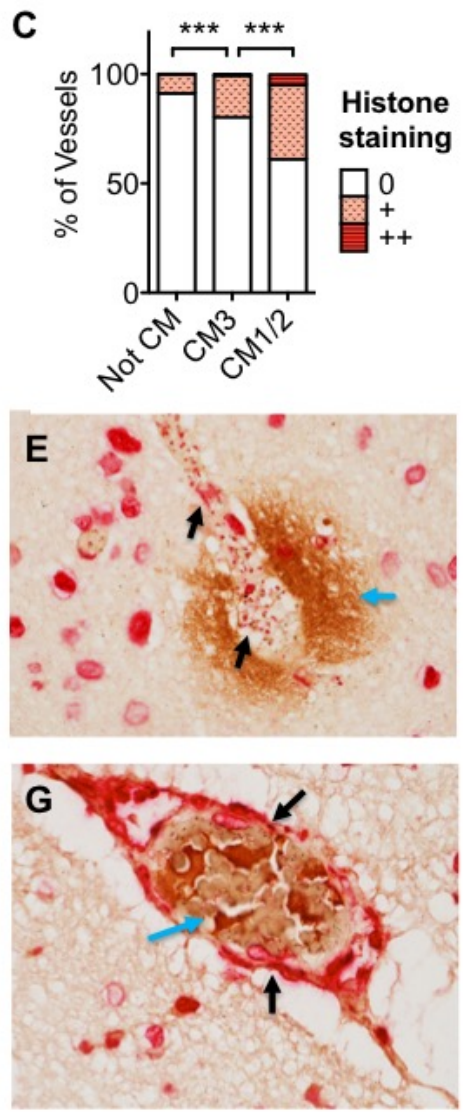

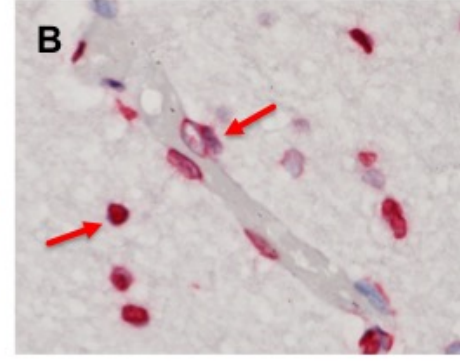

D
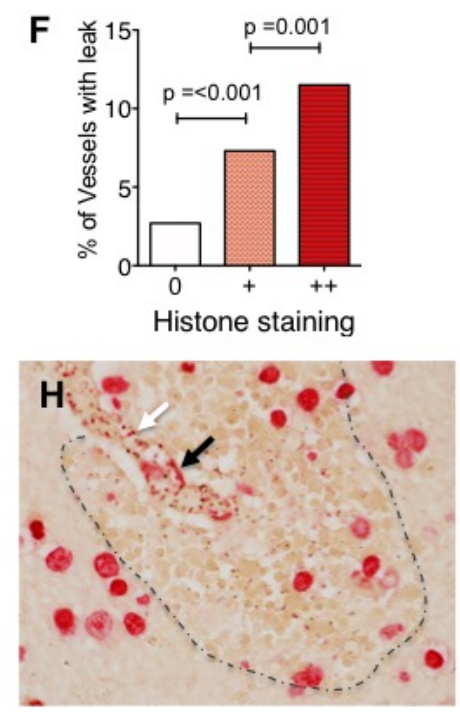

Figure 4. Histones accumulate at the endothelial surface in the cerebral microvasculature, associated with sequestration, coagulopathy and blood brain barrier breakdown. (A) Cerebral malaria case showing histone staining in close proximity with endothelial cell luminal surface (black arrows) and in both mammalian nuclei and malaria infected red blood cell (IE) nuclei (white arrow); (B) Non-CM case with no histone endothelial membrane binding, histone staining can be seen in mammalian cell nuclei (red arrows); (C) Extracellular histone staining is markedly increased in $\mathrm{CM} 1 / 2$ "true cerebral malaria" $(n=15)$ compared to 'faux CM' cases (peripheral parasitaemia, no sequestration in the brain and another cause of death at autopsy, CM3; $n=6$ ) or aparasitaemic non-CM cases ( $n=5)$; (D) In CM cases (CM1/CM2; n=15) there is a strong association between the degree of sequestration and the presence and strength of histone membrane staining. (E) Histone endothelial membrane staining (black arrows) co-localizing with fibrinogen extravasation (blue arrow), which is indicative of blood brain barrier breakdown. (F) Strong association between the extent of histone endothelial membrane staining and the presence of fibrinogen extravasation. (G) Histone membrane staining (black arrows) co-localizing with thrombosis (blue arrow). (H) Histone membrane staining (black arrow) co-localizing with a ring haemorrhage (edge demarcated by dotted line). 
A

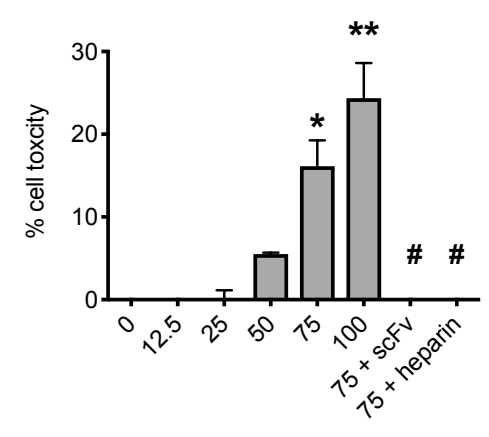

P. falciparum Histones $(\mu \mathrm{g} / \mathrm{ml})$

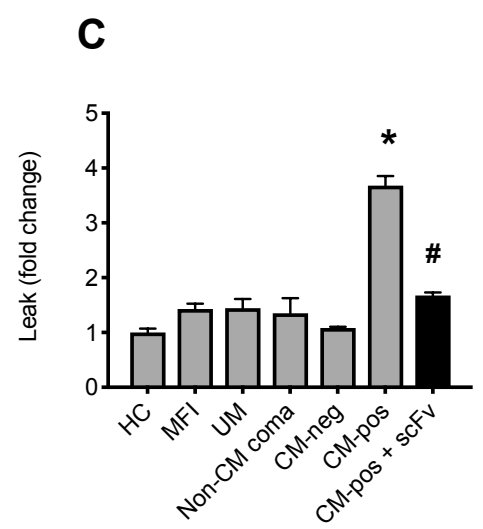

B

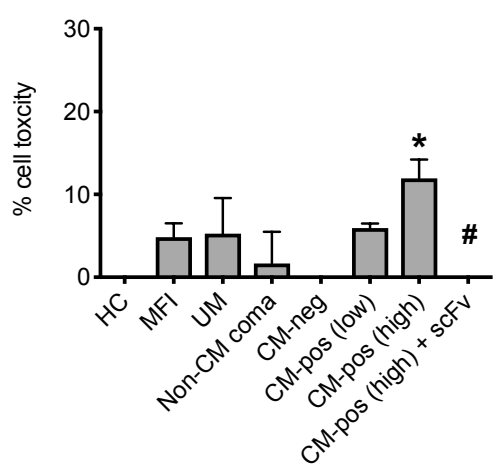

D

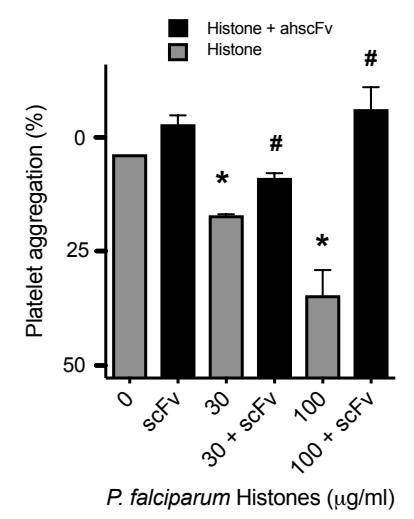

879
Figure 5. $P$. falciparum histones induce endothelial cell damage, permeability and platelet aggregation. A) HBMECs were treated for 1 hour with medium with or without purified $P$. falciparum histones (conc) \pm anti-histone single-chain Fragment variable (scFv) or nonanticoagulant heparin. Cell toxicity was determined by propidium iodide staining using flow cytometry. Data are expressed relative to cells treated with media alone (set to 0\%). ANOVA test $*=p<0.05$ when compared with untreated, $\#=p<0.05$ when compared with CM-pos high treated with histone alone; B) HBMECs were treated for 1 hour with serum from retinopathy positive $\mathrm{CM}$ ( \pm anti-histone $\mathrm{scFv}$ ), uncomplicated malaria, mild non-malarial febrile illness, non-malarial encephalopathy or retinopathy negative malaria and healthy controls. Cell toxicity (means \pm SD) relative to HBMEC treated with serum from healthy control cases (set to $0 \%$ ) are presented. C) Transwell permeability changes of HBMEC monolayer are expressed as fold changes in HRP pass through compared to cells treated with normal healthy serum. *ANOVA test shows a significant decrease compared with normal $(P<0.05), \# p<0.05$ when compared with retinopathy positive $\mathrm{CM}$ alone $\mathrm{D})$ Platelet rich plasma was incubated with different concentrations of $P$. falciparum histones \pm anti-histone scFv. Platelet aggregation (\%) (means \pm SD;) are presented following 15 mins incubation. ANOVA test, ${ }^{*} p<$ 0.05 when compared with untreated, \#p $<0.05$ when compared with that treated with histone alone. 3 biological replicates were used in all experiments except for $0 \mathrm{ug} / \mathrm{ml}$ and $75 \mathrm{ug} / \mathrm{ml}$ in A) (6 replicates; additional replicates as controls for heparin and anti-histone scFv assays and for $\mathrm{CM}$-pos high and $\mathrm{HC}$ in $\mathrm{B}$ ) (7 replicates; additional replicates performed for comparison with scFv and CM-pos with low histones). 
bioRxiv preprint doi: https://doi.org/10.1101/563551; this version posted March 20, 2019. The copyright holder for this preprint (which was not certified by peer review) is the author/funder. All rights reserved. No reuse allowed without permission.

\begin{tabular}{|c|c|c|c|c|c|c|}
\hline & Healthy controls & Mild febrile illness & $\begin{array}{l}\text { Uncomplicated } \\
\text { malaria }\end{array}$ & Non-malarial coma & CM-neg & CM-pos \\
\hline & $(n=21)$ & $(n=34)$ & $(n=50)$ & $(n=10)$ & $(n=48)$ & $(n=170)$ \\
\hline Age - months median (IQR) & $82(41-112)$ & $41(23-63)$ & $63(40-92)$ & $46(32-72)$ & $48(28-67)$ & $42(32-55)$ \\
\hline Female sex - no. (\%) & $8(38)$ & $15(44)$ & $26(52)$ & $1(10)$ & $23(48)$ & $86(50)$ \\
\hline HIV positive - no. (\%) & $0(0)$ & $0(0)$ & $0(0)$ & $0(0)$ & $4(8.3)$ & $15(8.8)$ \\
\hline $\begin{array}{l}\text { Axillary temperature - median } \\
\text { (IQR): }\end{array}$ & $36.8(36.1-36.8)$ & $38.2(37.9-38.6)$ & $38.3(37.9-39.0)$ & $38.6(38.4-39.0)$ & $38.7(37.7-39.6)$ & $38.7(38.7-39.6)$ \\
\hline $\begin{array}{l}\text { Pulse rate - beats/ minute - } \\
\text { median (IQR): }\end{array}$ & $117(104-125)$ & $136(113-154)$ & $137(119-147)$ & $140(119-157)$ & $143(130-164)$ & $150(138-167)$ \\
\hline $\begin{array}{l}\text { Systolic BP - mmHg - median } \\
\text { (IQR): }\end{array}$ & $112(103-118)$ & $117(107-123)$ & $114(107-122)$ & $100(94-110)$ & $98(91-105)$ & $95(89-106)$ \\
\hline $\begin{array}{l}\text { Respiratory rate - breaths/ min } \\
\text { - median (IQR): }\end{array}$ & $28(22-32)$ & $32(28-36)$ & $27(24-32)$ & $37(28-40)$ & $40(36-52)$ & $44(38-52)$ \\
\hline $\begin{array}{l}\text { Blood glucose - mmol/ L - } \\
\text { median (IQR): }\end{array}$ & $5.3(4.7-5.8)$ & $4.8(4.4-5.4)$ & $5.7(4.9-6.6)$ & $7.45(6.2-8.8)$ & $6.7(5.5-8.6)$ & $6.4(5.3-7.8)$ \\
\hline $\begin{array}{l}\text { Blood lactate - mmol/ L - } \\
\text { median (IQR): }\end{array}$ & $1.9(1.8-2.05)$ & $1.7(1.2-2.2)$ & $2.4(1.9-3.0)$ & $3.1(2.1-5.2)$ & $4.0(3.0-7.1)$ & $6.4(3.4-10.3)$ \\
\hline Hb - g/ L - median (IQR): & $104(98-111)$ & $115(105-120)$ & $93(76-107)$ & $91(82-92)$ & $82(69-102)$ & $64(51-77)$ \\
\hline $\begin{array}{l}\text { Platelets - x10\% L - median } \\
\text { (IQR): }\end{array}$ & $392(342-474)$ & 331 (239-388) & $132(82-185)$ & 335 (176-462) & $133(57-221)$ & $50(27-84)$ \\
\hline $\begin{array}{l}\text { Peripheral parasite density } \\
\left(\times 10^{3} / \mu \mathrm{l}\right) \text { - median (IQR): }\end{array}$ & 0 & 0 & $31(0.7-32)$ & 0 & $48(5-173)$ & $75(17-273)$ \\
\hline $\begin{array}{l}\text { Serum Histones - } \mu \mathrm{g} / \mathrm{mL} \text { - } \\
\text { median (IQR): }\end{array}$ & $1.3(0.0-3.0)$ & $0.8(0.0-3.8)$ & $1.5(0.4-5.6)$ & $3.2(1.0-12.7)$ & $6.3(2.2-23.5)$ & $24.6(8.4-69.4)$ \\
\hline
\end{tabular}

Table 1. Clinical characteristics of the children. IQR - interquartile range; HIV - Human 


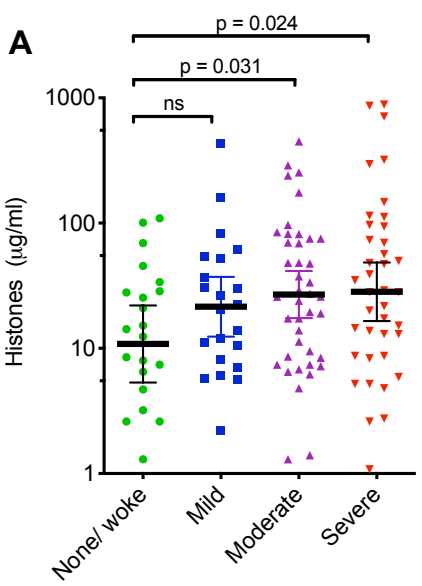

B

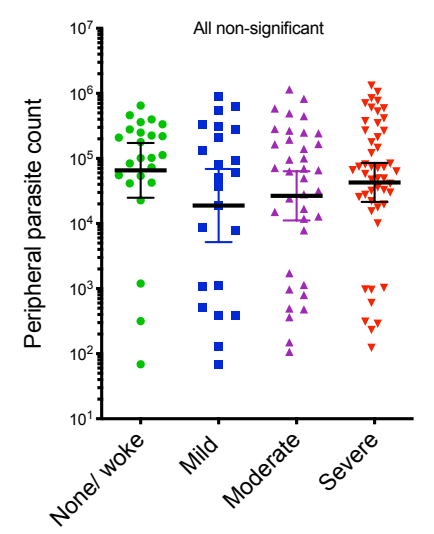

C
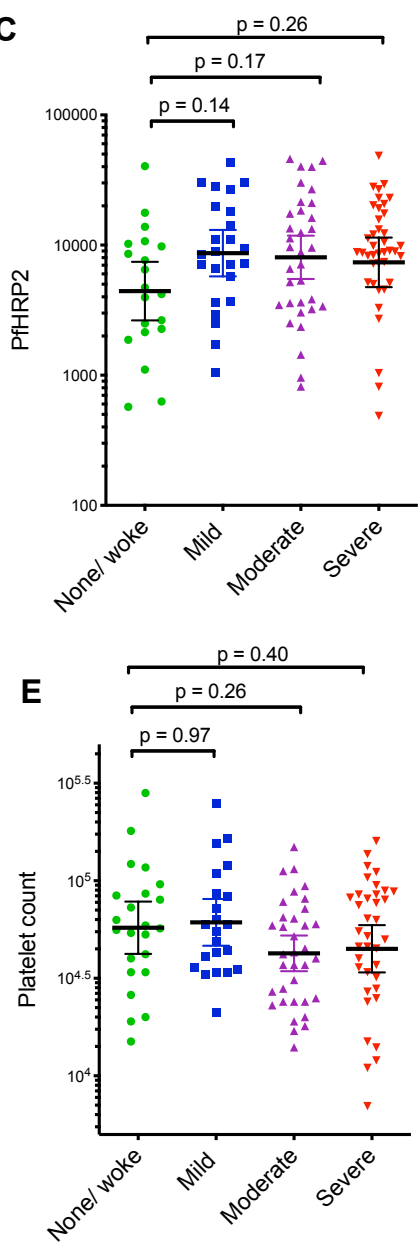

D

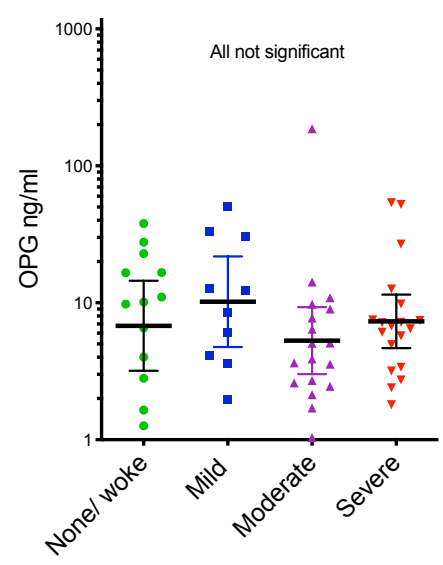

$\mathbf{F}$

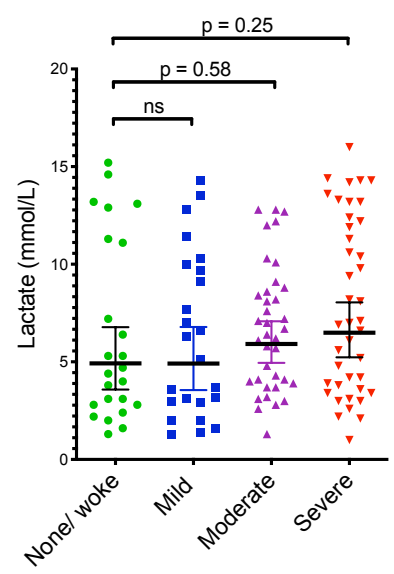




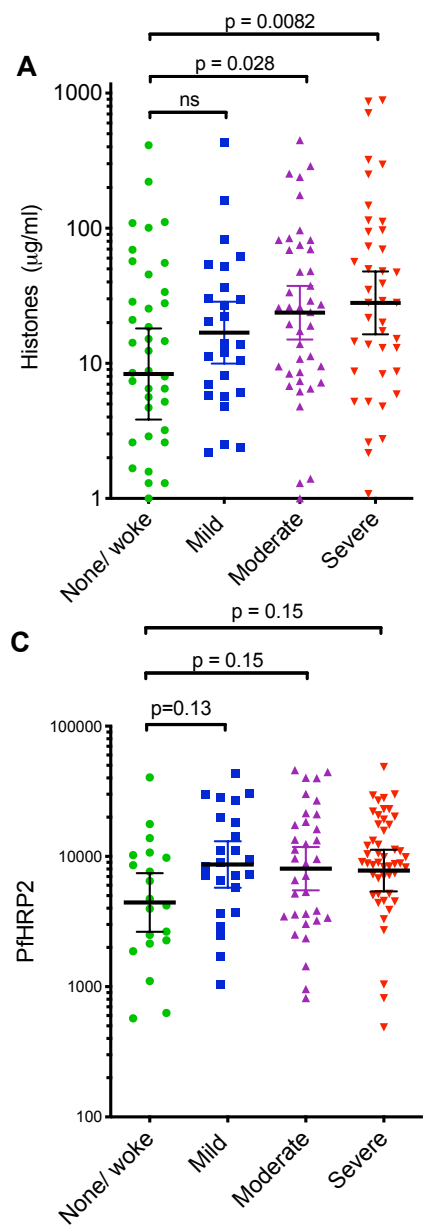

B

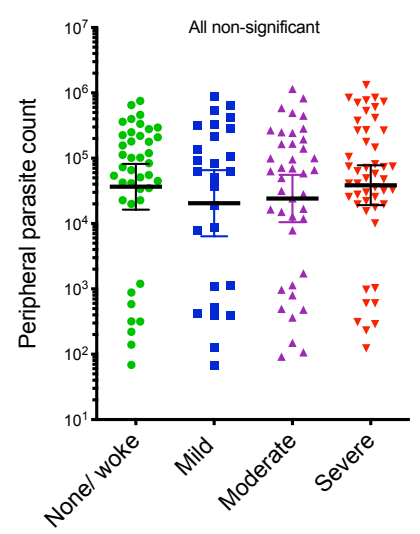

D

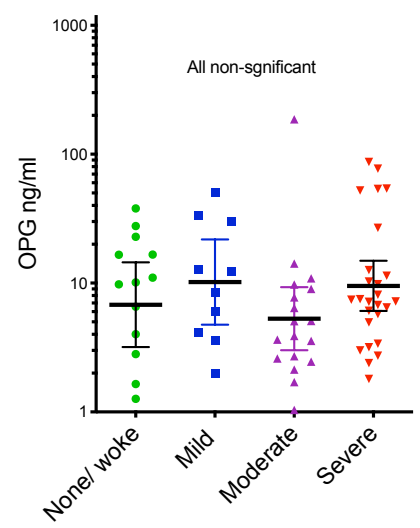

E
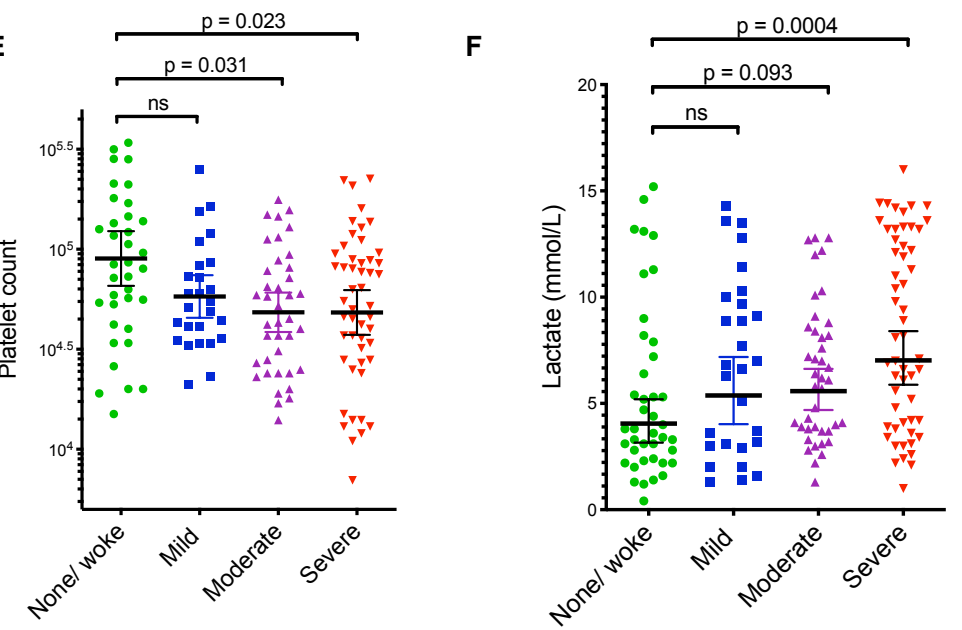

Fig S2. When both CM-pos and CM-neg cases are included, histones platelet count and 940 lactate are associated with the degree of brain swelling. 


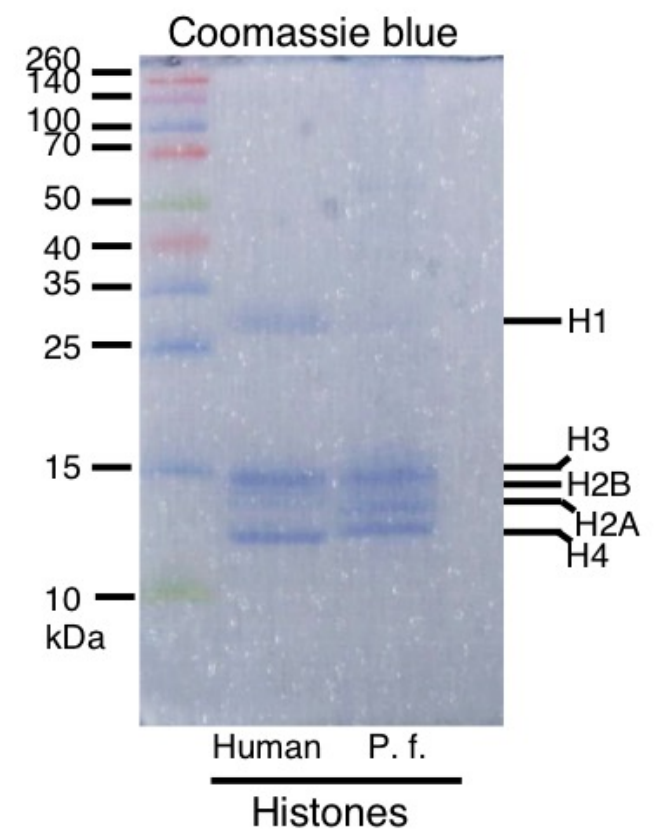

Fig. S3. Gel showing purified Plasmodium falciparum (P. f.) and human histones. Different core histones $(\mathrm{H} 2 \mathrm{~A}, \mathrm{H} 2 \mathrm{~B}, \mathrm{H} 3, \mathrm{H} 4)$ are identified by size. 


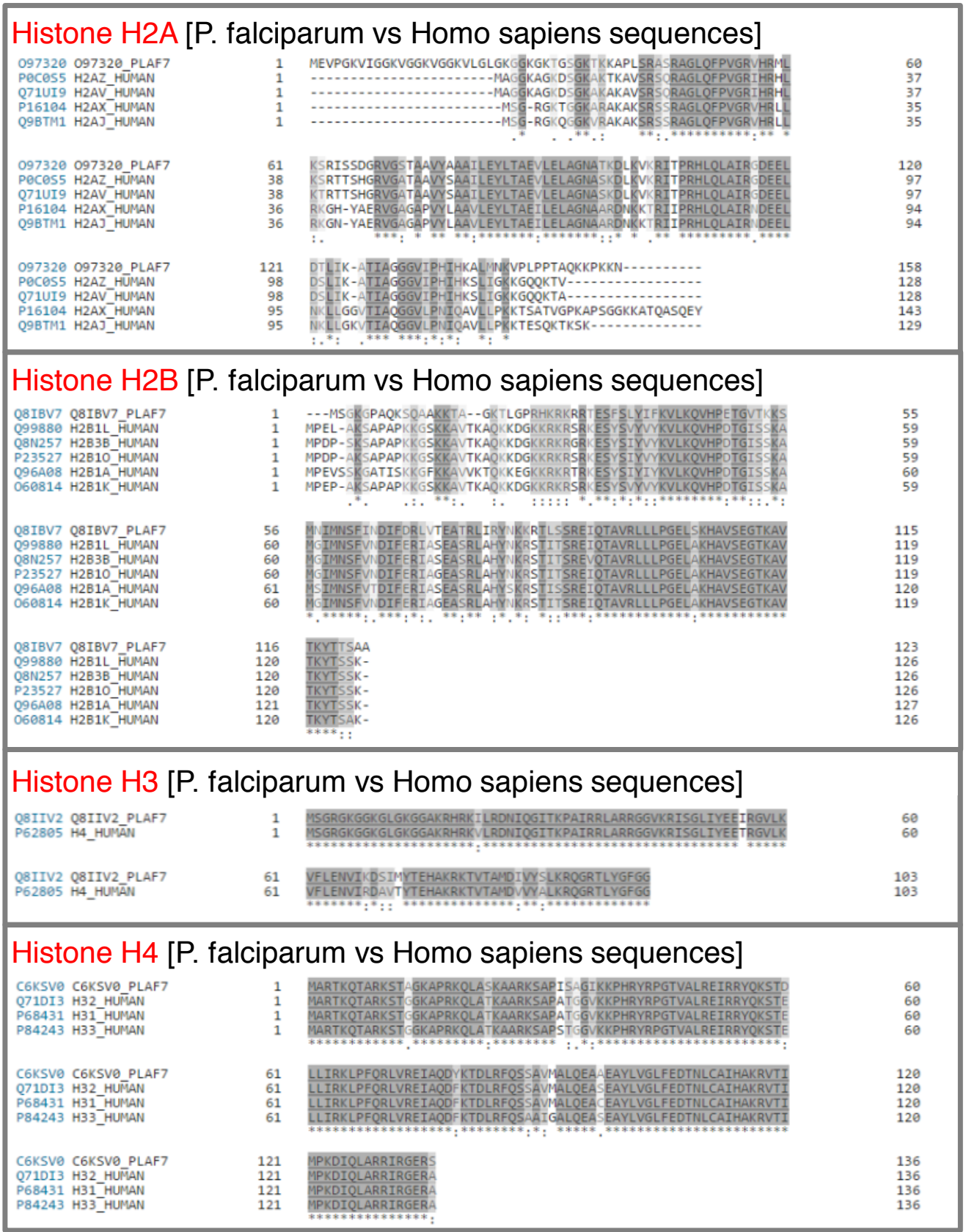

953 Fig. S4 Alignment of Homo sapiens and P. falciparum histones. Amino acid sequences of 954 individual histone variant proteins $(\mathrm{H} 2 \mathrm{~A}, \mathrm{H} 2 \mathrm{~B}, \mathrm{H} 3$ and $\mathrm{H} 4)$ were compared between Homo sapiens and $P$. falciparum. Using these data, we were able to identify heterologous (speciesspecific) histone peptide sequences (including protein ID numbers) for further downstream analysis. Dark grey = homologous amino acids; light grey and clear $=$ heterologous amino acids. 


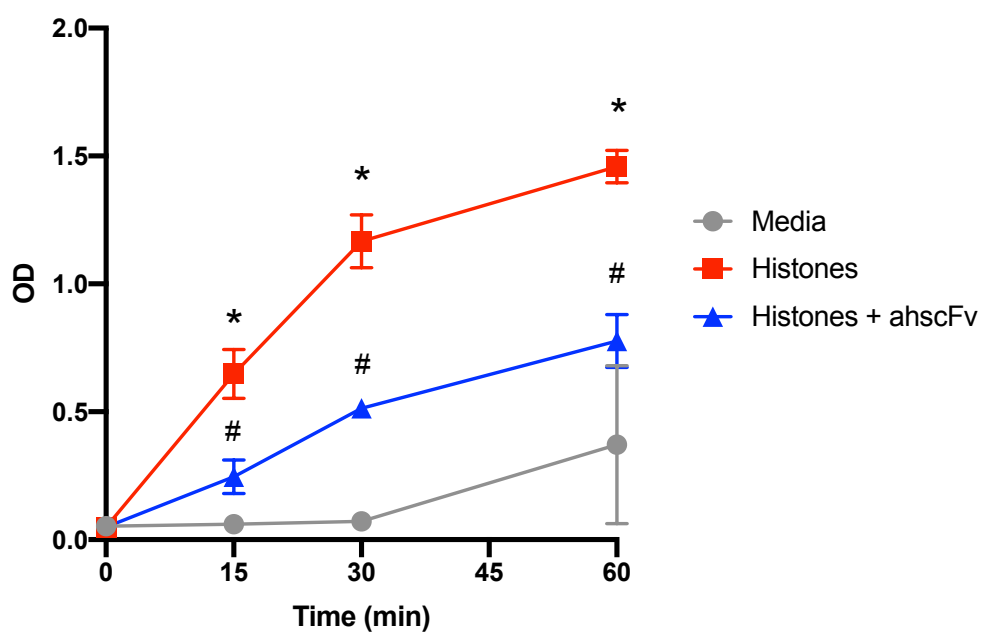

Fig S5. Time-course of barrier disruption of Primary human brain microvascular endothelial cells (HBMEC) by P. falciparum histones in a dual chamber system. Histone concentration $100 \mu \mathrm{g} / \mathrm{ml}$; Antibody concentration $200 \mu \mathrm{g} / \mathrm{ml}{ }^{*}$ = significant difference from media alone; \# = significant difference from histone alone (i.e. significant protection by ahscFv). 


\begin{tabular}{|c|c|c|c|c|c|}
\hline $\begin{array}{l}\text { Autopsy } \\
\text { Number }\end{array}$ & Classification & Diagnosis & $\begin{array}{l}\text { \% Vessels with } \\
\text { High Seq. }\end{array}$ & $\begin{array}{l}\text { \% Vessels with } \\
\text { Strong Histone } \\
\text { staining }\end{array}$ & $\begin{array}{c}\% \text { Vessels with } \\
\text { Leak }\end{array}$ \\
\hline 74 & CM1 & Cerebral malaria & 67.1 & 17.1 & 2.86 \\
\hline 79 & CM1 & Cerebral malaria & 73.3 & 6.7 & ${ }^{2.2} 998$ \\
\hline 84 & CM1 & Cerebral malaria & 60 & 0 & 0 \\
\hline 97 & CM1 & Cerebral malaria & 82.9 & 4.3 & 1.4000 \\
\hline 100 & $\mathrm{CM} 1$ & Cerebral malaria & 3.33 & 0 & 0 \\
\hline 60 & $\mathrm{CM} 2$ & Cerebral malaria & 55.7 & 1.4 & 1.4002 \\
\hline 62 & $\mathrm{CM} 2$ & Cerebral malaria & 65.2 & 0 & 1.4 \\
\hline 63 & CM2 & Cerebral malaria & 83 & 1.4 & 7.1. \\
\hline 64 & CM2 & Cerebral malaria & 85.6 & 2.2 & 3.3 \\
\hline 66 & CM2 & Cerebral malaria & 4.3 & 0 & 1.1007 \\
\hline 68 & CM2 & Cerebral malaria & 75.7 & 0 & 1.4 \\
\hline 75 & $\mathrm{CM} 2$ & Cerebral malaria & 82.9 & 24.3 & 1.4009 \\
\hline 78 & CM2 & Cerebral malaria & 22.3 & 5.7 & 13.3 \\
\hline 101 & CM2 & Cerebral malaria & 21.4 & 10 & $2 \theta 011$ \\
\hline 102 & CM2 & Cerebral malaria & 47.8 & 1.1 & 14.4 \\
\hline 43 & CM3 & Giant cell myocarditis & 0 & 0 & 5.16014 \\
\hline 49 & $\mathrm{CM} 3$ & $\begin{array}{l}\text { Ruptured Arteriovenous } \\
\text { malformation }\end{array}$ & 0 & 4.4 & 1.4 \\
\hline 54 & $\mathrm{CM} 3$ & Skull fracture & 0 & 0 & 10010 \\
\hline 71 & $\mathrm{CM} 3$ & $\begin{array}{c}\text { Subdural/intracerebral } \\
\text { hematomas }\end{array}$ & 0 & 0 & 4.4 \\
\hline 92 & CM3 & $\begin{array}{l}\text { Left ventricular failure with } \\
\text { pulmonary oedema }\end{array}$ & 0 & 0 & $\begin{array}{l}1019 \\
0 \\
1020\end{array}$ \\
\hline 93 & CM3 & $\begin{array}{c}\text { Clinical CM; Diagnosis } \\
\text { uncertain }\end{array}$ & 0 & 0 & 0 \\
\hline 44 & Non-CM & $\begin{array}{l}\text { Salicylate toxicity - } \\
\text { suspected }\end{array}$ & 0 & 1.4 & $\begin{array}{r}4.1023 \\
1024\end{array}$ \\
\hline 46 & Non-CM & $\begin{array}{l}\text { Severe (non-malarial) } \\
\text { anemia }\end{array}$ & 0 & 0 & 0 \\
\hline 59 & Non-CM & Reye's syndrome & 0 & 0 & $\begin{array}{l}1 . \frac{1}{4} 0<0 \\
1027\end{array}$ \\
\hline 65 & Non-CM & Reye's syndrome & 0 & 0 & 0 \\
\hline 88 & Non-CM & $\begin{array}{l}\text { Subdural hematoma, head } \\
\text { trauma }\end{array}$ & 0 & 0 & 01029 \\
\hline
\end{tabular}

Table S1. Summary of post-mortem cases. Clinical pathologist's diagnosis at autopsy and proportion of vessels with each of: (1) high sequestration (seq; sequestration involving $>50 \%$ of vessel lumen); (2) strong histone staining and; (3) leak (fibrinogen staining adjacent to a vessel). 